\title{
Radar-Observed Bulk Microphysics of Midlatitude Leading-Line Trailing-Stratiform Mesoscale Convective Systems
}

\author{
SHAWN L. HANDLER ${ }^{\mathrm{a}}$ AND CAMERON R. HOMEYER \\ School of Meteorology, University of Oklahoma, Norman, Oklahoma
}

(Manuscript received 29 January 2018, in final form 23 July 2018)

\begin{abstract}
In 2013, all NEXRAD WSR-88D units in the United States were upgraded to dual polarization. Dual polarization allows for the identification of precipitation particle shape, size, orientation, and concentration. In this study, dual-polarization NEXRAD observations from 34 recent events are used to identify the bulk microphysical characteristics of a specific subset of mesoscale convective systems (MCSs), the leading-line trailing-stratiform (LLTS) MCS. NEXRAD observations are used to examine hydrometeor distributions in relative altitude to the $0^{\circ} \mathrm{C}$ level and as a function of storm life cycle, precipitation source (convective or stratiform), and storm environment. The analysis reveals that graupel particles are the most frequently classified hydrometeor class in a layer extending from the $0^{\circ} \mathrm{C}$-level altitude to approximately $5 \mathrm{~km}$ above within the convective region. Below the $0^{\circ} \mathrm{C}$ level, rain is the most frequently classified hydrometeor, with small hail and graupel concentrations present throughout the LLTS system's life cycle. The stratiform precipitation region contains small graupel concentrations in a shallow layer above the $0^{\circ} \mathrm{Clevel}$, with pristine ice crystals being classified as the most frequently observed hydrometeor at higher altitudes and snow aggregates being classified as the most frequently observed hydrometeor at lower altitudes above the environmental $0^{\circ} \mathrm{C}$ level. Variations in most unstable convective available potential energy (MUCAPE) have the largest impact on the vertical distribution of hydrometeors, because more-unstable environments are characterized by a greater production of rimed ice.
\end{abstract}

\section{Introduction}

Mesoscale convective systems (MCSs) have been the focus of many previous studies because of their unique dynamical characteristics and impact on the large-scale circulation, their substantial contribution to precipitation (especially during the summer), and their association with severe and/or hazardous weather at Earth's surface (tornadoes, hail, wind, lightning, and flash flooding). Representing MCSs in numerical models requires a detailed understanding of their dynamical and microphysical (cloud and precipitation particle) characteristics, of which the latter are not as well understood. The dynamical characteristics of MCSs have been studied extensively in the tropics and midlatitudes (e.g., Zipser 1969; Houze 1989, 2004; Houze et al. 1989;

\footnotetext{
${ }^{\text {a }}$ Current affiliation: Cooperative Institute for Mesoscale Meteorological Studies, Norman, Oklahoma.
}

Corresponding author: Shawn Handler, shawn.handler@ noaa.gov
Biggerstaff and Houze 1991). MCSs contain both convective and stratiform precipitation (Houze et al. 1990; Houze 2004) and develop internal circulations as their life cycles progress. They are typically defined as "a cumulonimbus cloud system that produces a contiguous precipitation area $\sim 100 \mathrm{~km}$ or more in at least one direction," which we adopt in this study (Houze 2004). The most common MCS type, known as the leading-line trailing-stratiform (LLTS) MCS (Parker and Johnson 2000), features a front-to-rear ascending flow originating at the leading edge of the gust front, which then travels through the convective region and into the upper levels of the stratiform region, and a rear-to-front descending flow originating at the base of the stratiform cloud terminating near the leading convection (Smull and Houze 1985, 1987). The rear-to-front flow (commonly referred to as a rear-inflow jet or RIJ) arises as a dynamical response to the mean heating within the convective line (Schmidt and Cotton 1990; Pandya and Durran 1996; Fovell 2002).

Microphysical processes directly affect buoyancy and convective fluxes through condensate loading and latent 
heating/cooling (Bryan and Morrison 2012). These impacts can influence the dynamical characteristics of organized convection. One of the more notable impacts is through the development of the low-level cold pool. The low-level cold pool is driven by diabatic cooling, which is primarily associated with the evaporation of raindrops and the melting of snow aggregates in the stratiform rain region of MCSs. The balance between the low-level cold pool and environmental shear is argued to be important for sustaining MCSs by affecting their rate of evolution (e.g., Rotunno et al. 1988).

Much of the knowledge of the kinematic and microphysical structure of MCSs can be attributed to numerous field campaigns, such as the Preliminary Regional Experiment for STORM-Central (PRE-STORM; Cunning 1986), the Bow Echo and Mesoscale Convective Vortex Experiment (BAMEX; Davis et al. 2004), and the Midlatitude Continental Convective Clouds Experiment (MC3E; Jensen et al. 2016). Both ground-based and airborne observations were used to document these characteristics and their associated processes. Airborne observations have provided extensive in situ observations of the stratiform region, providing particle size distributions (PSDs) and "habits" (particle type) for validation and development of model parameterizations. However, because of the hazards associated with flying through or near convection, the convective region remains poorly sampled from aircraft. In addition, all aircraft observations are limited as a result of the narrow spatial and temporal extent of observations within individual MCSs. On the other hand, ground-based radar observations can provide continuous sampling of MCSs with large spatial and temporal coverage, with some loss of information at the smallest spatial scales that is due to limitations of radar sampling.

More recent studies have used polarimetric (dual polarization) radar observations to understand the bulk microphysics of MCSs, particularly focusing on tropical systems associated with the Madden-Julian oscillation (MJO) and on systems in West Africa (e.g., Bouniol et al. 2010; Evaristo et al. 2010; Rowe and Houze 2014; Barnes and Houze 2014). Rowe and Houze (2014) concluded that the frequency of individual hydrometeor types varied with storm size and MJO activity, but the mean shape of the vertical profiles did not vary a considerable amount unless the radar echo was partitioned into convective and stratiform components. Barnes and Houze (2014, hereinafter BH14) analyzed the microphysical characteristics relative to mesoscale airflow patterns of mature MJO convection. Although it has been documented that MCSs are kinematically similar throughout the world, the hydrometeor structure of tropical MCSs most likely differs from continental MCSs because of the differences in aerosol content, thermodynamic profile, and convective intensity between marine and continental air masses (Zipser 1977; LeMone and Zipser 1980; Zipser and LeMone 1980; Keenan and Carbone 1992; LeMone et al. 1998).We therefore hypothesize that the hydrometeor structures of midlatitude continental MCSs are different from tropical oceanic MCSs.

To the authors' knowledge, there have not been any studies utilizing a large dataset of polarimetric radar observations and linking those observations to microphysical processes within midlatitude LLTS MCSs over the continental United States (CONUS). Previous studies have evaluated a limited number of case studies to arrive at their conclusions, with many of the cases studied being those observed during the field campaigns outlined above. The conclusions drawn from individual cases may not always be representative of a large number of storms. Inherent variability in the hydrometeor distributions may arise from variations in their environmental characteristics, synoptic forcing, and organization.

In this study, polarimetric observations from Next Generation Weather Radar (NEXRAD) Weather Surveillance Radar-1988 Doppler (WSR-88D) systems in the CONUS of 34 recent MCSs are used to develop an understanding of the bulk microphysical characteristics of midlatitude LLTS systems. We focus solely on these systems given that they are the most frequently observed. We employ techniques to merge individual radar observations into large-area, three-dimensional composites for analysis; a fuzzy-logic hydrometeor classification algorithm; and a radar echo classification algorithm to enable a detailed physical understanding of these events. Bulk hydrometeor distributions within LLTS systems are examined in terms of the near-storm environment in which they form, their life cycle (developing, mature, and dissipating stages), and their internal structure (convective or stratiform).

\section{Data and methods}

\section{a. Radar observations}

This study utilizes level-II polarimetric radar data from the NEXRAD WSR-88D network to quantify bulk hydrometeor distributions of 34 continental midlatitude MCSs (see Table 1). Each NEXRAD volume used in this study includes the following polarimetric variables: radar reflectivity at horizontal polarization $Z_{H}$, differential reflectivity $Z_{\mathrm{DR}}$, differential propagation phase shift $\phi_{\mathrm{DP}}$, and copolar correlation coefficient 
TABLE 1. Observed MCS cases.

\begin{tabular}{lcc}
\hline \hline Case date & Time range (UTC) & $\begin{array}{c}\text { Composite domain } \\
\text { bounds }\left({ }^{\circ} \mathrm{N},{ }^{\circ} \mathrm{E}\right)\end{array}$ \\
\hline 31 May 2013 & $2200-1800$ & $34-43,264-278$ \\
9 May 2013 & $0400-1400$ & $30-44,254-270$ \\
5 Jun 2013 & $0000-1600$ & $33-42,248-270$ \\
6 Jun 2013 & $2200-1400$ & $30-37,255-266$ \\
12 Jun 2013 & $2100-1100$ & $37-45,267-284$ \\
16 Jun 2013 & $2200-1500$ & $31-41,256-268$ \\
21 Jun 2013 & $0400-1900$ & $40-49,260-276$ \\
23 Jul 2013 & $1000-0200$ & $29-34,266-280$ \\
4 Apr 2014 & $0200-1800$ & $29-42,264-278$ \\
27 May 2014 & $0000-1700$ & $28-35,256-270$ \\
1 Jun 2014 & $1800-1100$ & $34-43,256-268$ \\
3 Jun 2014 & $1800-1500$ & $37-46,256-275$ \\
8 Jun 2014 & $2200-1000$ & $30-37,267-280$ \\
10 Jun 2014 & $0000-2100$ & $28-35,260-273$ \\
15 Jun 2014 & $0000-1300$ & $34-44,256-268$ \\
16 Jun 2014 & $1700-1000$ & $40-50,260-275$ \\
30 Jun 2014 & $1700-0700$ & $39-47,263-280$ \\
2 Jul 2014 & $1800-0300$ & $40-48,283-294$ \\
3 Jul 2014 & $1800-0800$ & $38-48,280-294$ \\
8 Jul 2014 & $0000-1100$ & $35-44,260-274$ \\
2 Oct 2014 & $1900-0900$ & $29-41,262-273$ \\
27 Apr 2015 & $0100-2000$ & $27-35,258-275$ \\
28 May 2015 & $2000-1100$ & $28-36,256-266$ \\
7 Jun 2015 & $2000-1300$ & $37-43,265-279$ \\
18 Jun 2015 & $0300-1500$ & $38-46,254-265$ \\
22 Jun 2015 & $0600-1900$ & $40-48,260-276$ \\
13 Jul 2015 & $0000-1500$ & $39-49,261-277$ \\
14 Jul 2015 & $1800-0500$ & $32-37,267-280$ \\
18 Jul 2015 & $31-50,261-275$ \\
17 Nov 2015 & $36-43,262-278$ \\
26 Apr 2016 & $0000-1500$ & $31-42,257-269$ \\
27 Apr 2016 & $0200-1400$ & \\
\hline & $2200-1100$ & \\
\hline
\end{tabular}

$\rho_{\mathrm{HV}}$. Rather than $\phi_{\mathrm{DP}}$, which suffers from a considerable amount of random noise, this study uses one-half of its range derivative- the specific differential phase $K_{\mathrm{DP}}$ for analysis. In this study, $K_{\mathrm{DP}}$ is computed using firstorder centered differencing on $\phi_{\mathrm{DP}}$ observations that are first smoothed using a $7.5-\mathrm{km}$ radial running-mean filter. These variables provide important microphysical information that can be used to classify hydrometeor distributions in storms. Hydrometeor size can be inferred from $Z_{H}$ since $Z \sim D^{6}$, which is valid at $\mathrm{S}$ band for these storms (i.e., reflectivity is proportional to the sixth moment of the PSD), although particle concentration can also change $Z_{H}$. Shape information is provided by both $Z_{\mathrm{DR}}$ and $K_{\mathrm{DP}}$. Since $Z_{\mathrm{DR}}$ is a reflectivity-weighted observation of particle shape, it reveals information about the shape of the largest hydrometeor in a sampling volume (Seliga and Bringi 1976, 1978). In addition, $K_{\mathrm{DP}}$ provides information on the concentration (or total mass) of anisotropic hydrometeors in a sampling volume. Last, $\rho_{\mathrm{HV}}$ is a measure of the diversity of hydrometeors within a sampling volume, including large variations in orientation, phase, or shape. For more detailed information on the polarimetric radar variables and their physical interpretations, see available textbooks (e.g., Doviak and Zrnić 1993; Bringi and Chandrasekar 2001) and review papers (e.g., Straka et al. 2000; Kumjian 2013a,b,c).

High-resolution, large-area composites of multiple radar volumes were created by merging all individual radar observations, which were obtained from the National Centers for Environmental Information (NCEI; NOAA/NWS/ROC 1991), onto a common grid following the methods used in the publicly available Gridded NEXRAD WSR-88D Radar (GridRad; http:// gridrad.org/) dataset (Homeyer 2014; Homeyer and Kumjian 2015). To summarize briefly, observations within $300 \mathrm{~km}$ in range from each individual radar contributing to the domain of an MCS throughout its life cycle were binned in space and time at 5-min intervals on a $0.02^{\circ} \times 0.02^{\circ}(\sim 2 \mathrm{~km})$ longitude-latitude grid with $1-\mathrm{km}$ vertical resolution. The radar observations were weighted spatially in range and in time relative to that of the composite using a Gaussian weighting function. An example of the large-area composite, including vertical cross sections of each of the four polarimetric variables used in this study, is shown in Fig. 1.

The compositing technique employed in this study is ideal for trying to understand the bulk characteristics of these systems, since it allows for analysis of the entire volume and life cycle of an MCS. However, given the $1-\mathrm{km}$ vertical resolution of the merged radar data, microphysical processes on scales smaller than the composite may be missed altogether. To overcome this limitation and analyze hydrometeor distributions at a finer vertical resolution $(250 \mathrm{~m})$, we also analyze the original single-radar observations for each MCS at close ranges to the radar. Since the polarimetric observations are typically less reliable beyond ranges of $120 \mathrm{~km}$, due to radar beam broadening and nonuniform beam filling (e.g., Loney et al. 2002; Ryzhkov 2007), we focus on observations within that range, specifically within 60 and $120 \mathrm{~km}$. Examining the polarimetric variables within these ranges will not erase this limitation completely, but it should lessen the impact of such artifacts on our results.

\section{b. Reanalysis output}

Details of the atmospheric environment were obtained from North American Regional Reanalysis (NARR; Mesinger et al. 2006) output in this study. NARR provides atmospheric state variables over the CONUS at a horizontal resolution of $32 \mathrm{~km}$, at 29 constant pressure 

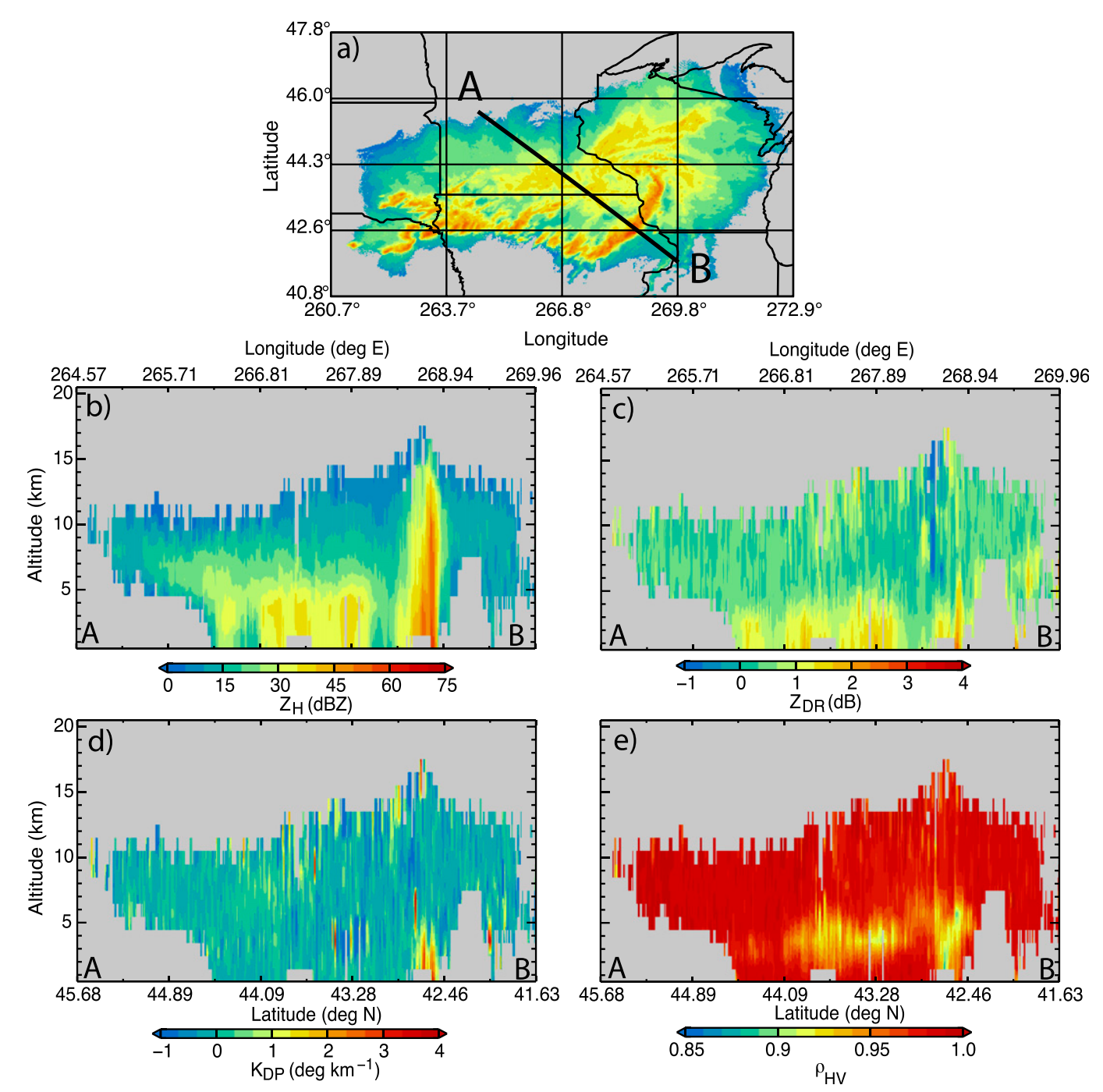

FIG. 1. Examples of the polarimetric NEXRAD WSR-88D composites for the 16-17 Jun 2014 MCS: (a) columnmaximum map of $Z_{H}$, and vertical cross sections of (b) $Z_{H}$, (c) $Z_{\mathrm{DR}}$, (d) $K_{\mathrm{DP}}$, and (e) $\rho_{\mathrm{HV}}$. The thick black line labeled A-B in (a) shows the path of the vertical cross sections in (b)-(e).

levels in the vertical, and in 3-h increments (NCEP 2005). NARR was chosen over other high-resolution analyses because of data archive longevity and reliability. Although not shown, the derived most unstable convective available potential energy (MUCAPE) field and the height of the environmental $0^{\circ} \mathrm{C}$ level showed little difference from corresponding fields calculated using proximity soundings for a subset of the cases tested.

In this study, NARR profiles of temperature and specific humidity are used to compute MUCAPE, and the $0^{\circ} \mathrm{C}$-level altitude was retained for hydrometeor classification (discussed below) and for plotting purposes. Given that wind shear (and its interaction with the low-level cold pool) plays a significant role in the evolution, longevity, and intensity of MCSs (e.g., Weisman and Klemp 1982; Weisman et al. 1988; Rotunno et al. 1988), NARR profiles of $u$ and $v$ wind components were used to compute the magnitude of the $0-6-\mathrm{km}$ bulk wind shear parameter. Linear interpolation in space and time was used to match the NARR output to the radar observations. While poorly handled fronts and other discontinuities from linear interpolation could introduce errors to the analysis, no such instances were found in the cases analyzed here.

\section{c. Radar echo classification}

For classification of observed radar echo in this study, the "storm labeling in three dimensions" (SL3D; Starzec et al. 2017) algorithm was used. SL3D classifies 
echo into five categories: convective updraft, convection, precipitating stratiform, nonprecipitating stratiform, or ice-only anvil. SL3D utilizes $Z_{H}, Z_{\mathrm{DR}}, K_{\mathrm{DP}}$, and the altitude of the environmental $0^{\circ} \mathrm{C}$ level to classify the radar echo. Only the convective updraft, convection, and precipitating stratiform categories are used for analysis in this study. For simplicity, we combine the convection and convective updraft echo into a single convection category for analysis. SL3D classifications were produced for all of the merged radar data. These classifications were extracted in space and time to enable similar analyses of the singleradar observations.

\section{d. MCS evolutionary stage classification}

For analysis of the radar observations in this study, a quasi-objective method for classifying the life cycle of each MCS was employed. In particular, time series of the mean $Z_{H}=15 \mathrm{~dB} Z$ echo-top altitude within regions of SL3D-classified convection were subjectively evaluated to identify periods of increasing echo-top altitudes during the development of an MCS (the "developing" stage), near-constant echo-top altitudes following development (the "mature" stage), and decreasing echotop altitudes thereafter (the "dissipating" stage). An example of this classification approach is provided in Fig. 2. The strict cutoff times for each life-cycle stage were perturbed by $\pm 3 \mathrm{~h}$ for each event to examine any subjective sensitivity. Modifications to the cutoff time within this window did not significantly change the results.

\section{e. Hydrometeor classification algorithm}

To provide a physical understanding of the bulk microphysics of MCSs from polarimetric radar observations, we employ a "fuzzy logic" hydrometeor classification algorithm (HCA) in this study. Although there are many HCAs that have been developed for S-band radars in the literature, which can provide differing representations of storm microphysics, we employ the operationally implemented algorithm designed specifically for NEXRAD WSR-88D instruments in this study (Park et al. 2009, hereinafter P09). The P09 $\mathrm{HCA}$ uses six radar measurements- $Z_{H}, Z_{\mathrm{DR}}, K_{\mathrm{DP}}$, $\rho_{\mathrm{HV}}$, the standard deviation (SD) of $Z_{\mathrm{DR}}\left[\mathrm{SD}\left(Z_{\mathrm{DR}}\right)\right]$, and $\operatorname{SD}\left(\phi_{\mathrm{DP}}\right)$ - to identify 10 different hydrometeor classes. The P09 hydrometeor classes are dry aggregated snow (DS), wet snow (WS), ice crystals of various orientation (CRY), graupel (GRA), big drops (BD), light-moderate rain (RA), heavy rain (HR), and rain-hail mixture ( $\mathrm{RH})$. In addition, two nonmeteorological classes are identified by $\mathrm{P} 09$ : ground clutter/anomalous propagation (GC/AP) and

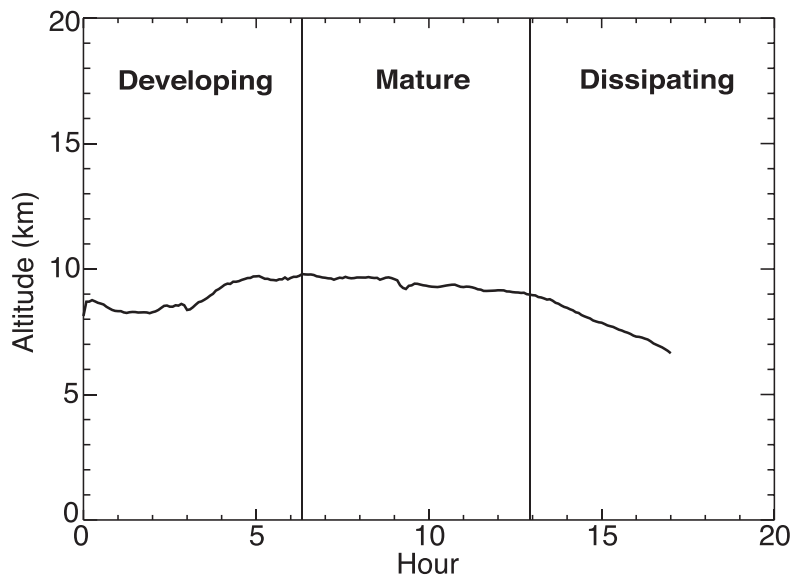

FIG. 2. Time series of the convective mean $Z_{H}=15 \mathrm{~dB} Z$ echotop altitude for the 16-17 Jun 2014 MCS. Vertical lines denote the subjectively determined times of change in life-cycle stage (from developing to mature to dissipating).

biological scatters (BS). The reader is referred to Park et al. (2009) for more detailed information on the design of the P09 HCA.

For this study, a few modifications were made to the P09 algorithm to allow for better isolation of hydrometeor classes (see Table 2). Herein, we discuss the most important changes and modifications that best suit the datasets used. Since we have our own quality control algorithms that remove nonmeteorological echoes, the two standard deviation membership functions were omitted (because of their main importance in distinguishing between meteorological and nonmeteorological echoes). The confidence vector $\mathbf{Q}$ was set equal to 1 , because we expect the random fluctuation errors in polarimetric fields to be averaged out over the large number of cases used, and the different radars and radar viewing angles should lead to no preferred bias for the geometry-dependent artifacts (see Homeyer 2014; Homeyer and Kumjian 2015). However, setting $\mathbf{Q}$ equal to 1 for the single-radarbased analysis is an assumption we make and a risk we take for which artifacts, such as nonuniform beam filling, attenuation, and partial beam blockage, may be more prominent and skew the single-radar-based results. We are thankful that attenuation is not as likely for S-band radars, and we account for systematic $Z_{\mathrm{DR}}$ biases using a "natural scatter" approach (see Homeyer and Kumjian 2015). Graupel was also allowed to be classified in the stratiform region since previous in situ observations of the 3 June 1989 MCS and subsequent modeling studies (see Zrnić et al. 1993) did note the presence of graupel in the stratiform region. Wet snow was only allowed to be classified within $1 \mathrm{~km}$ of the $0^{\circ} \mathrm{C}$ altitude given that 
TABLE 2. List of the nine P09 HCA modifications.

\begin{tabular}{|c|c|}
\hline 1) & $\begin{array}{l}\text { The SL3D algorithm was used for radar echo } \\
\text { classification }\end{array}$ \\
\hline 2) & $\begin{array}{l}\mathrm{SD}\left(Z_{\mathrm{DR}}\right) \text { and } \mathrm{SD}\left(\phi_{\mathrm{DP}}\right) \text { membership functions were } \\
\text { omitted }\end{array}$ \\
\hline 3) & Set $\mathbf{Q}=1$ \\
\hline 4) & Class GRA: $Z_{H} \leq 50 \mathrm{~dB} Z$ \\
\hline 5) & Use the $0^{\circ} \mathrm{C}$ altitude provided by NARR \\
\hline 6) & $\begin{array}{l}\text { Class WS is allowed only within } 1 \mathrm{~km} \text { of the } 0^{\circ} \mathrm{C} \text { altitude } \\
\text { based on analyses of } \rho_{\mathrm{HV}}\end{array}$ \\
\hline 7) & $\begin{array}{l}\text { Rain class is allowed no more than } 4 \mathrm{~km} \text { above } 0^{\circ} \mathrm{C} \\
\text { altitude }\end{array}$ \\
\hline 8) & Class GRA is allowed in stratiform regions \\
\hline 9) & $\begin{array}{l}\text { The } Z_{\mathrm{DR}} \text { membership function is simplified to a range of } \\
0-1 \mathrm{~dB} \text { for the RH class to isolate hail (HA; our } \\
\text { modified class) }\end{array}$ \\
\hline
\end{tabular}

previous studies (e.g., Zrnić et al. 1993; Fabry and Zawadzki 1995; Zhang et al. 2008; Andric et al. 2013) have shown the radar bright band is typically confined to within $1 \mathrm{~km}$ of the melting level. Last, we seek to create a pure hail class as to eliminate the rain-hail mixture class in P09. Since larger, nonmelting hail typically tumbles as it falls, the polarimetric return of $Z \mathrm{DR}$ should be close to $0 \mathrm{~dB}$. We therefore restricted the $Z D R$ membership function to a range of $0-1 \mathrm{~dB}$. The authors are aware of the newest upgrades to the P09 HCA as discussed in Ryzhkov et al. (2013) and Ortega et al. (2016); however, we are only concerned with the presence of hail and not necessarily with the size of hail (which these papers address).

This newly modified P09 HCA is applied to the NEXRAD WSR-88D observations. For analyses of convection, $\mathrm{BD}, \mathrm{RA}$, and $\mathrm{HR}$ are grouped into a single "rain" class. GRA, the modified hail class (HA), and CRY are left as separate classes (since DS classifications are not allowed within convective cores per P09). For analyses of stratiform regions, the CRY, DS, and WS classes are evaluated separately along with the rain class. It is important to note that the scattering properties of the hydrometeors and subsequent radar returns are what decide the hydrometeor classification. Therefore, the returned hydrometeor class classified by the HCA is considered the most dominant hydrometeor class. Although a certain hydrometeor class may be dominant at a specific location within a single storm at a specific time, that same hydrometeor class may not be the most frequently observed class over a larger collection of storms (and most certainly is not the only hydrometeor class present at any specific location). We therefore focus on the bulk, or overall frequency, of the hydrometeor classes over the collection of events.

\section{Results}

\section{a. Observed radar variables}

A common approach for examining bulk characteristics of polarimetric radar variables is contouredfrequency-by-altitude diagrams (CFADs; Yuter and Houze 1995). In most prior studies, convection and stratiform regions are analyzed separately due to their well-known microphysical differences and vertical structure. Here, we examine convection and stratiform region CFADs of the four polarimetric variables available in the NEXRAD WSR-88D observations: $Z_{H}$, $Z_{\mathrm{DR}}, K_{\mathrm{DP}}$, and $\rho_{\mathrm{HV}}$.

\section{OBSERVED RADAR VARIABLES}

CFADs of the NEXRAD WSR-88D polarimetric radar observations were computed for both the radar composites (1-km vertical resolution) and the singleradar observations $(0.25-\mathrm{km}$ vertical resolution). In these analyses, single-radar observations correspond to those within $60 \mathrm{~km}$ of the radar location. For each analysis, results are presented as a function of LLTS system evolution.

Convective source region CFADs from the radar composites and single-radar observations are shown in Fig. 3. The observed $Z_{H}$ CFADs are generally characterized by frequency maxima at decreasing $Z_{H}$ values with increasing altitude, with nearly vertically oriented $Z_{H}$ distributions below the $0^{\circ} \mathrm{C}$ level. Frequency maxima are highest and extend to larger $Z_{H}$ values below the $0^{\circ} \mathrm{C}$ level during the mature evolutionary stage, with broader maxima at lower $Z_{H}$ during the developing and dissipating stages. The $Z_{H}$ distributions at altitudes above the $0^{\circ} \mathrm{C}$ level extend to higher values during the developing stage, and incrementally shift to lower $Z_{H}$ during the mature and dissipating stages.

For the convective developing and mature stages, $Z_{\mathrm{DR}}$ values are in excess of $2 \mathrm{~dB}$ within relatively modest $Z_{H}$ regions below the $0^{\circ} \mathrm{C}$ level, which are indicative of large, oblate raindrops possibly in relatively low concentrations (Kumjian and Ryzhkov 2009, 2012). The $K_{\mathrm{DP}}$ CFADs show similar characteristics below the $0^{\circ} \mathrm{C}$ level with a maximum of $\sim 1^{\circ} \mathrm{km}^{-1}$, indicating small- to medium-sized drops (e.g., Hubbert et al. 1998; Straka et al. 2000; Loney et al. 2002; Kumjian 2013b). The $Z_{\mathrm{DR}}$ and $K_{\mathrm{DP}}$ CFADs show frequency maxima near $0 \mathrm{~dB}$ and $0^{\circ} \mathrm{km}^{-1}$ above the $0^{\circ} \mathrm{C}$ level, respectively, with broader $Z_{\mathrm{DR}}$ distributions skewed to values near $1 \mathrm{~dB}$ at echo top, indicating pristine ice crystals. Observed $\rho_{\mathrm{HV}}$ CFADs in convection show frequency maxima near 0.98 at all depths and during all evolutionary stages, with broader 
Radar Composite
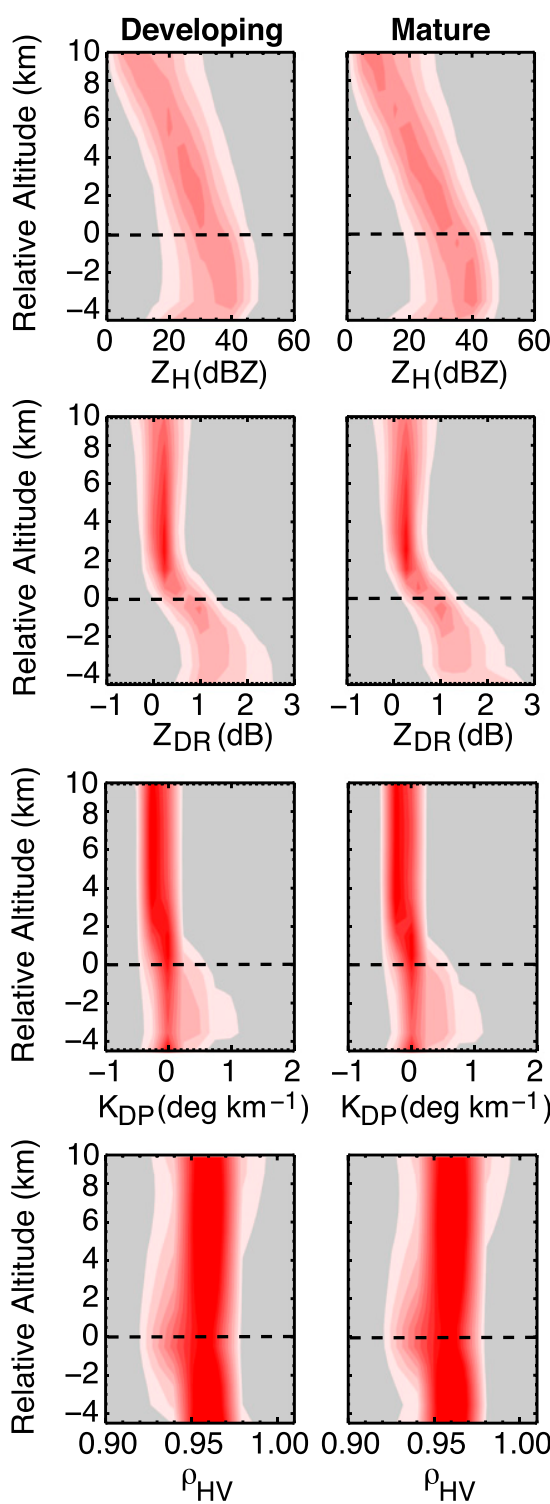

$\mathrm{K}_{\mathrm{DP}}\left(\operatorname{deg} \mathrm{km}^{-1}\right)$
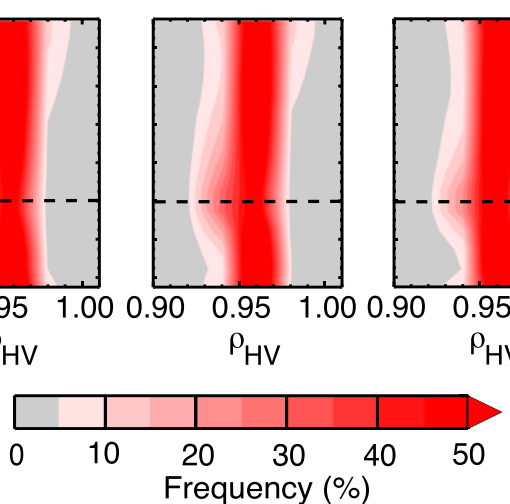

Single Radar
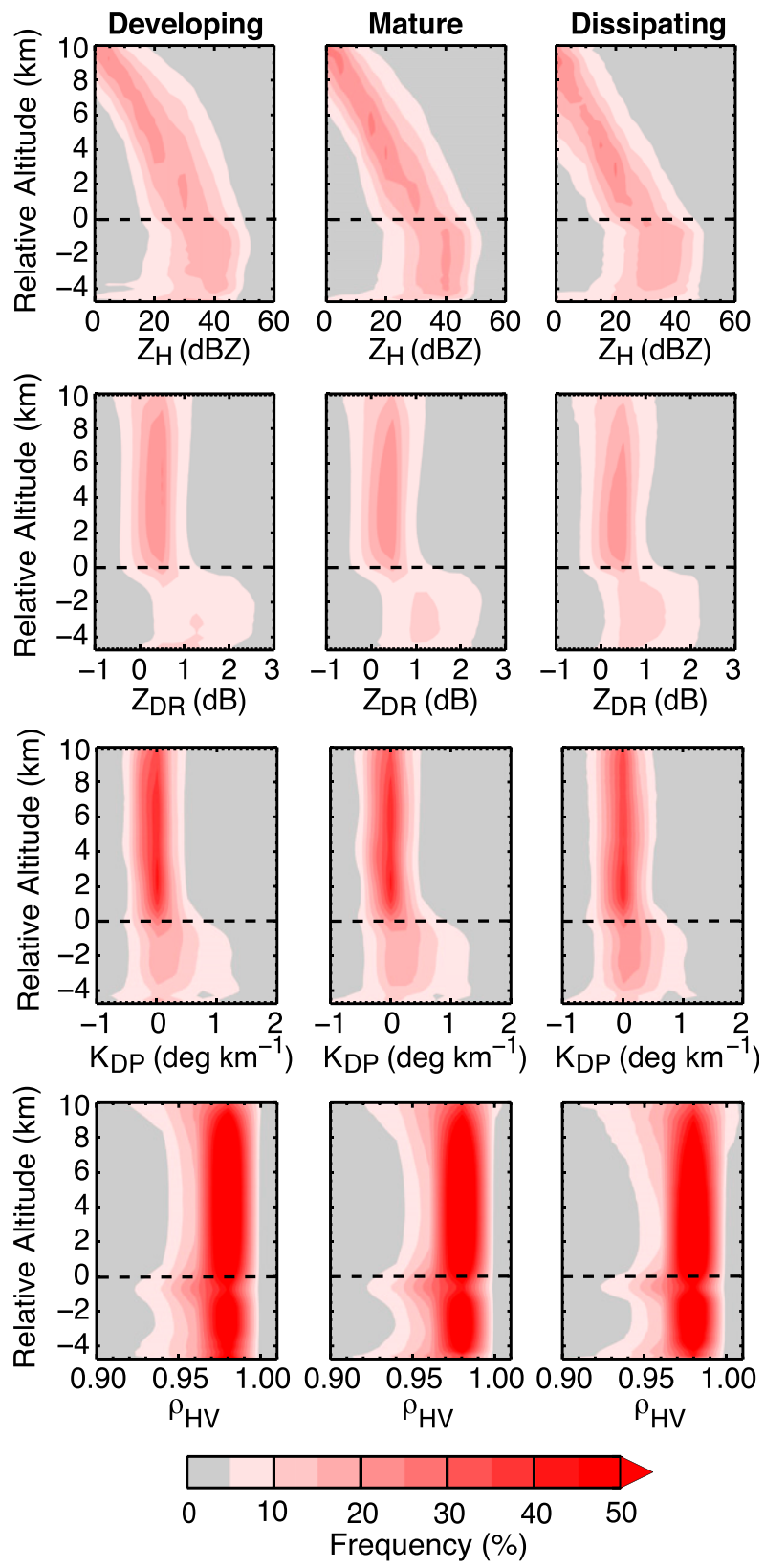

FIG. 3. Polarimetric radar variable CFADs for convective regions of LLTS from (left) the merged NEXRAD WSR-88D observations and (right) a single-radar perspective. The $0^{\circ} \mathrm{C}$-level altitude is from NARR, and the altitude bin resolution is $1 \mathrm{~km}$. The dashed black line in each panel represents the altitude of the $0^{\circ} \mathrm{C}$ level, and profiles are binned relative to the environmental $0^{\circ} \mathrm{C}$-level altitude.

distributions in the 1-km layer immediately above and below the $0^{\circ} \mathrm{C}$ level extending to a value of about 0.925 . This reduction, collocated with enhanced $Z_{\mathrm{DR}}$ above the $0^{\circ} \mathrm{C}$ level, indicating mixed-phase hydrometeors, extends somewhat vertically and is skewed to altitudes above the $0^{\circ} \mathrm{C}$ level likely indicating the extent of lofting and/or freezing of supercooled raindrops within the mixed-phase region (e.g., Hall et al. 1984; Caylor and Illingworth 1987; Brandes et al. 1995; Smith et al. 1999; Kumjian and Ryzhkov 2008; Kumjian et al. 2012). The vertical extent of reduced $\rho_{\mathrm{HV}}$ values above the $0^{\circ} \mathrm{C}$ level decreases as the LLTS system life cycle progresses.

Stratiform source region CFADs from the radar composites and single-radar observations are shown in 
Radar Composite
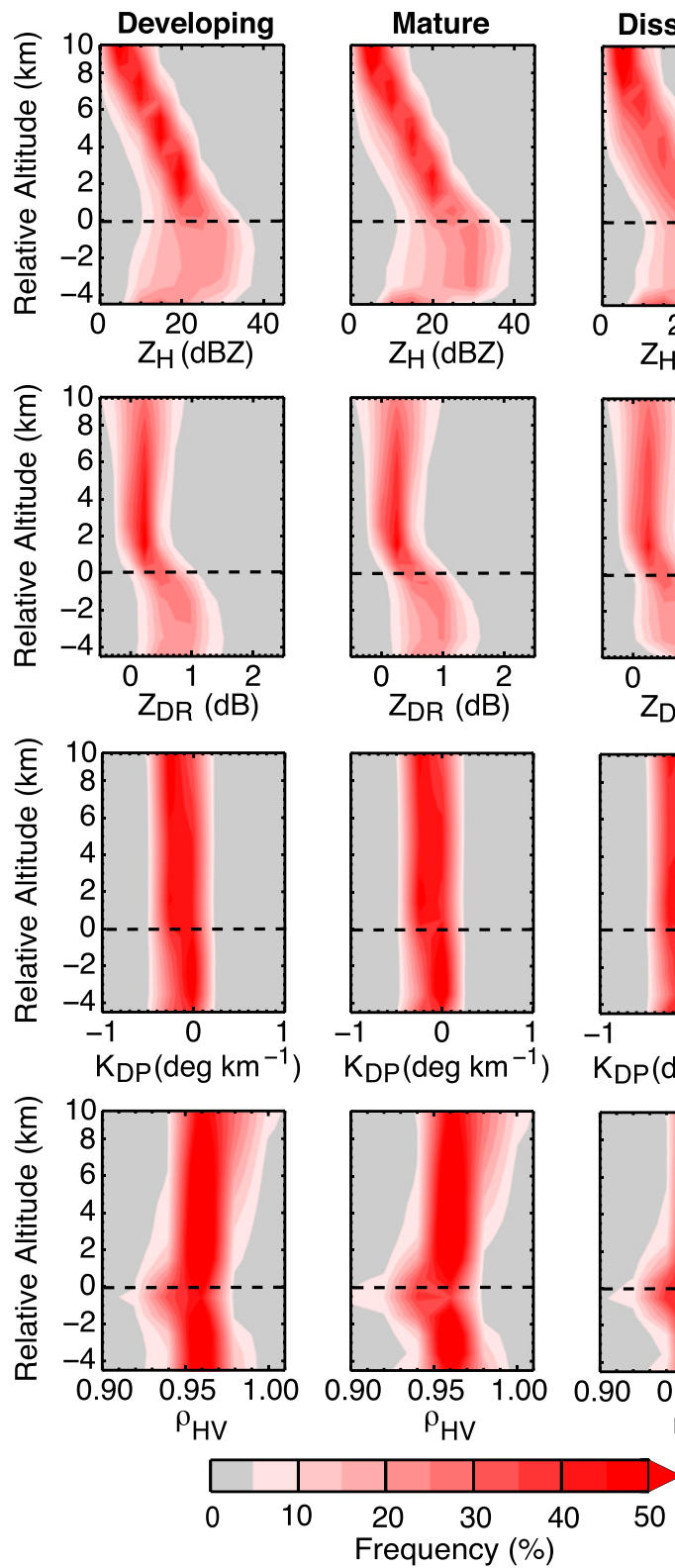
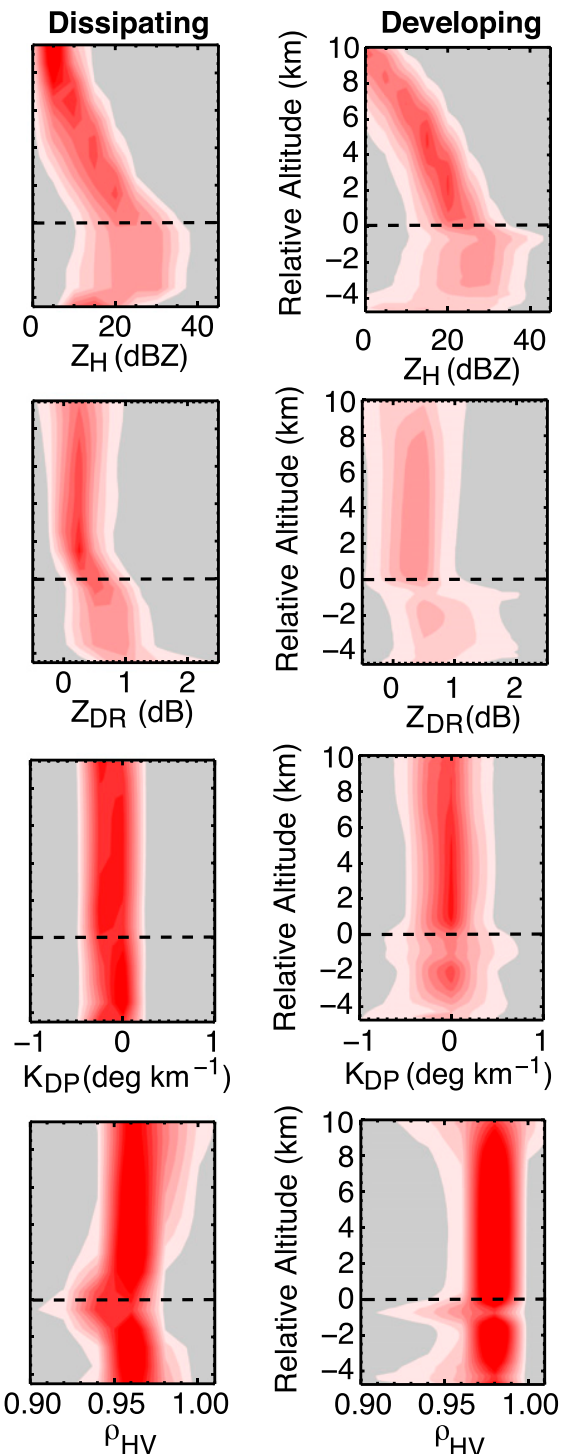

Single Radar
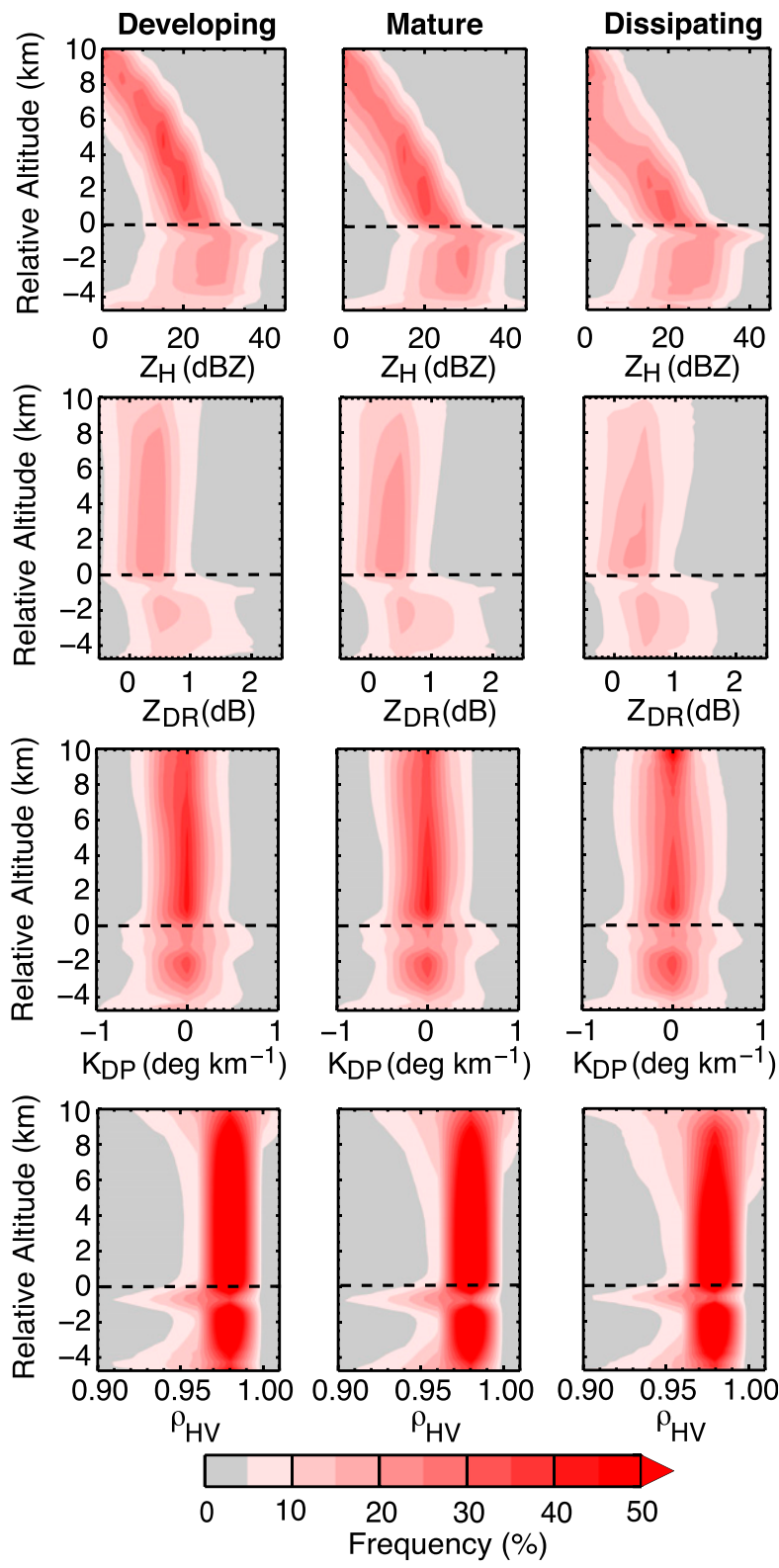

FIG. 4. As in Fig. 3, but for the stratiform region of observed LLTS MCSs.

Fig. 4. Larger differences are found between the composite-based analyses and single-radar analyses in the stratiform region, especially with respect to the brightband signature below the $0^{\circ} \mathrm{C}$ level. The brightband signature (i.e., maximum in $Z_{H}$ and $Z_{\mathrm{DR}}$ or minimum in $\rho_{\mathrm{HV}}$ just below the $0^{\circ} \mathrm{C}$ level) arises from the large variability of irregular shapes/orientations of melting aggregates, and the subsequent differences in dielectric constants of water and ice (Austin and Bemis 1950). Observed CFADs of $Z_{H}$ in the stratiform region are generally characterized by large frequency maxima at $Z_{H}<10 \mathrm{~dB} Z$ aloft, with the diagonal structure of the maxima extending to higher $Z_{H}$ with decreasing altitude to the $0^{\circ} \mathrm{C}$ level. The $Z_{H}$ CFAD slope and maximum $Z_{H}$ observed decreases at altitudes above the $0^{\circ} \mathrm{C}$ level as the MCS life cycle progresses, indicating less growth (i.e., aggregation) as the convection weakens and less ice is detrained to the stratiform region. Similar to the convective region, observed CFADs in the stratiform region show 
the highest frequencies and highest $Z_{H}$ values below the $0^{\circ} \mathrm{C}$ level during the mature stage. The $Z_{H}$ bright band is confined to the $0-1-\mathrm{km}$ layer below the $0^{\circ} \mathrm{C}$ level (most evident in the single-radar analysis).

Observed $Z_{\mathrm{DR}}$ CFADs in the stratiform region show broad maxima between 0 and $1 \mathrm{~dB}$, with values generally less than $1.5 \mathrm{~dB}$ overall. The $Z_{\mathrm{DR}}$ brightband feature is less pronounced than that for $Z_{H}$ and is only distinguishable at the lowest frequencies (or extreme values). Above the $0^{\circ} \mathrm{C}$ level, $Z_{\mathrm{DR}}$ distributions show maxima near $0 \mathrm{~dB}$, indicating aggregates (e.g., Bader et al. 1987; Andric et al. 2013) at lower altitudes and broader distributions extending to values near $1 \mathrm{~dB}$ at higher altitudes, indicating the increasing prevalence of horizontally oriented pristine ice crystals aloft (e.g., Straka et al. 2000). The $Z_{\mathrm{DR}}$ distributions above the $0^{\circ} \mathrm{C}$ level become broader as the life cycle progresses, again indicating a reduction in aggregation during the dissipating stage. Observed $K_{\mathrm{DP}}$ CFADs within the stratiform regions show little variability in altitude or as a function of evolutionary stage, with the only notable signature being positive/ negative oscillations in the $0-1-\mathrm{km}$ layer below the $0^{\circ} \mathrm{C}$ level from single-radar observations. These oscillations have been attributed to backscatter differential phase shift in nonspherical particles (most often the result of resonance-sized nonspherical particles; Trömel et al. 2013, 2014), which is not removed by the $K_{\mathrm{DP}}$ processing algorithm here, and possibly nonuniform beam filling (Zrnić et al. 1993; Ryzhkov 2007). Observed $\rho_{\mathrm{HV}}$ CFADs also show a clear brightband signature in the $0-1-\mathrm{km}$ layer below the $0^{\circ} \mathrm{C}$ level, with reductions to lower values in the single-radar observations.

\section{b. Hydrometeor frequency profiles}

To develop a more physical understanding of the bulk microphysics of LLTS MCSs (i.e., the typical vertical extent and prevalence of various hydrometeor classes), we examine the vertical distribution of hydrometeors in the following subsections. Profiles based on the modified P09 HCA are presented for the radar observations. Both the mean and standard deviation of the frequency of each hydrometeor class are shown to demonstrate the average classification quantity at a given altitude and inherent variability, respectively.

Hydrometeor frequency profiles based on application of the modified P09 HCA to the NEXRAD WSR-88D polarimetric radar observations were computed for both the radar composites (1-km vertical resolution) and the single-radar observations $(0.25-\mathrm{km}$ vertical resolution). In these analyses, two ranges of single-radar observations are analyzed: those within 60 and $120 \mathrm{~km}$ of the radar location. As done for the CFAD analyses, results are presented as a function of LLTS system evolution.

Convective and stratiform echo source region hydrometeor frequency distributions for the radar composites are shown in Fig. 5. The observed hydrometeor profiles show a "graupel nose" feature within convection in a layer extending from the $0^{\circ} \mathrm{C}$ level to $\sim 5 \mathrm{~km}$ above. This graupel nose has been observed within tropical convection, but the vertical depth of the feature is smaller (Rowe and Houze 2014). The depth (and overall frequency) of this graupel nose decreases as the evolutionary stage progresses, giving way to increasing frequencies of various ice crystals at higher altitudes. Rain hydrometeors are most frequently classified below the $0^{\circ} \mathrm{C}$ level and $\sim 10 \%-20 \%$ of the time in a layer up to $3 \mathrm{~km}$ above the $0^{\circ} \mathrm{C}$ level within convection, similar to the results of Evaristo et al. (2010) and Barnes and Houze (2014). Hail in the convective region is seldom classified. Although the prominence of hail is small in the overall frequency space, hail is more frequently observed in both the developing and mature stages in a shallow layer above the $0^{\circ} \mathrm{C}$ level.

Hydrometeor frequency profiles in the stratiform regions reveal that graupel has marginal overall observed frequencies up to $10 \%$ of the time at altitudes $\sim 1 \mathrm{~km}$ above the $0^{\circ} \mathrm{C}$ level, with the largest frequencies found during the mature evolutionary stage. However, given the vertical resolution of the composites used in this study, it is possible that larger snow aggregates are being misclassified as graupel particles. The P09 membership functions for DS and GRA overlap for most of the polarimetric variables. Therefore, it is possible that the percentages shown for graupel above the $0^{\circ} \mathrm{C}$ level may in fact be smaller. Further investigation is need for a more definitive answer.

Wet snow is classified up to $10 \%$ of the time within the $1-\mathrm{km}$ layer immediately below the $0^{\circ} \mathrm{C}$ level within stratiform precipitation. Last, a clear indication of the aggregation process is observed above the $0^{\circ} \mathrm{C}$ level via the inverse relationship between high pristine ice crystal frequencies at high altitudes and the higher snow aggregate frequencies at altitudes just above the $0^{\circ} \mathrm{C}$ level. The crossover point of the overall frequencies between these two classes decreases in altitude as the LLTS system life cycle progresses, possibly revealing differences in favored growth mechanisms or the size of ice crystals detrained from the leading convection.

Figure 6 shows the hydrometeor frequency profiles for convection and stratiform regions from the single-radar observations within 60 and $120 \mathrm{~km}$ of a radar's location. 

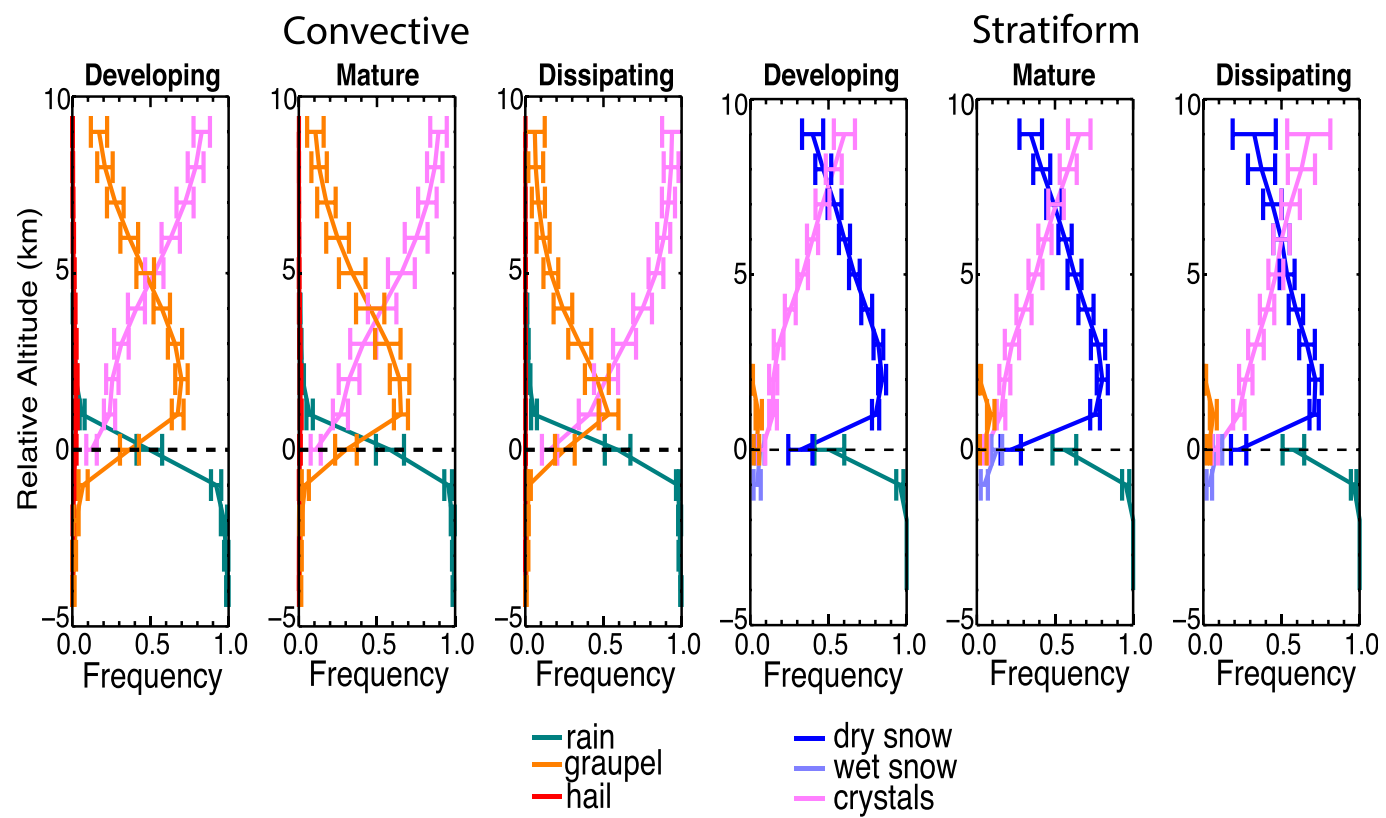

FIG. 5. Weighted mean hydrometeor frequency distribution profiles from HCA output using merged NEXRAD WSR-88D observations of all 34 LLTS system events, as a function of precipitation source (convective or stratiform) and evolutionary stage (developing, mature, and dissipating). Observations are binned relative to the environmental $0^{\circ} \mathrm{C}$-level altitude at $1-\mathrm{km}$ resolution. The dashed horizontal line represents the $0^{\circ} \mathrm{C}$-level altitude. A frequency of 1 is equal to $100 \%$.

Results of the single-radar observations are comparable to those from the radar composites, with a few unique results. First, higher frequencies of graupel are classified at the expense of raindrops at altitudes below the $0^{\circ} \mathrm{C}$ level within convective regions. Second, hail frequencies are slightly higher within convective regions in the single-radar observations, especially above the $0^{\circ} \mathrm{C}$ level. Third, the vertical extent of elevated (supercooled) rain frequencies above the $0^{\circ} \mathrm{C}$ level is deeper in single-radar observations within convection, with frequencies up to $10 \%$ at $4 \mathrm{~km}$ above the $0^{\circ} \mathrm{C}$ level. Fourth, the crossover point in ice crystal/snow aggregate overall frequency in the stratiform region occurs at lower altitudes in the single-radar observations. Fifth, variability in the hydrometeor classification distribution is larger in the single-radar profiles. This may be due to fewer observations relative to the composites but could also be attributed to beam broadening or other artifacts.

\section{c. Environment sensitivities}

To assess the impact of environmental characteristics (i.e., MUCAPE and vertical wind shear) on LLTS MCS hydrometeor distributions using the radar observations, an approach to identify individual convective cores within the leading line of each LLTS MCS was required. To facilitate this analysis, local maxima of the $30-\mathrm{dBZ}$ echo-top altitude were identified at each radar composite time as the centers of individual cores. All polarimetric radar variables and the modified P09 HCA classifications were then extracted within a $24-\mathrm{km}$ radius of the core locations for analysis. The vertical distributions of the hydrometeor classes were calculated on a core-by-core basis using the HCA classifications within the $24-\mathrm{km}$ circle, for which the results are presented below.

Figure 7 shows the sensitivity of the frequency at which the rain, various crystals, graupel, and hail hydrometeor classes are observed within convective cores in altitude relative to the $0^{\circ} \mathrm{C}$ level, color filled by the corresponding mean MUCAPE value. Color-filled boxes are shown only if the respective bin locations contained greater than $50 \%$ of the number of convective cores observed. Figure 7 demonstrates that, as MUCAPE increases, the overall frequency of graupel classifications above the $0^{\circ} \mathrm{C}$ level increases and the frequency of various ice crystals decreases, which is in agreement with the result that is expected on the basis of the well-established relationship between riming and instability (i.e., the more unstable the environment is, the faster the upward motion within convection will be and the greater the supercooled water content above the $0^{\circ} \mathrm{C}$ level will be, which is necessary for generation of graupel—and hail—via riming). For example, making 


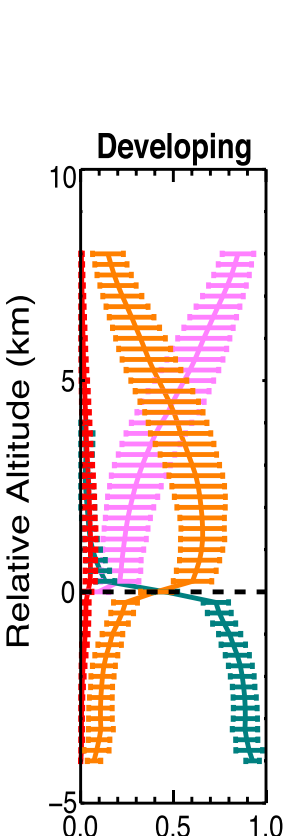

Convective
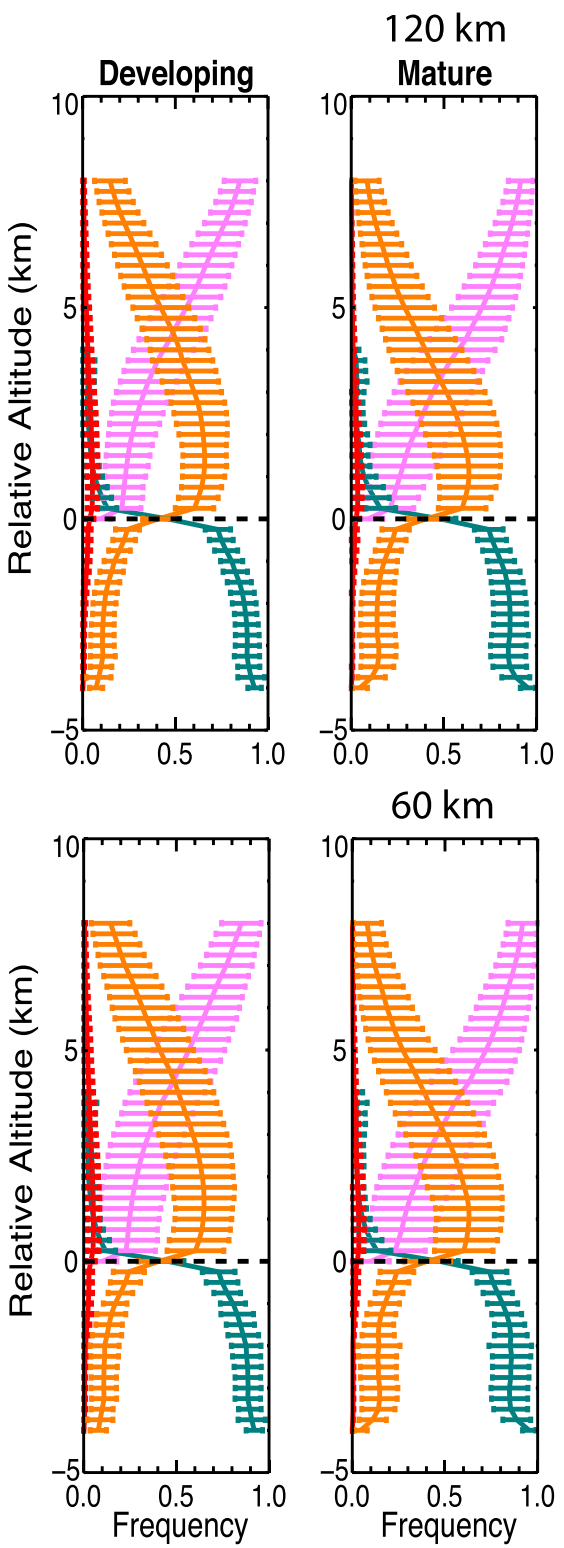
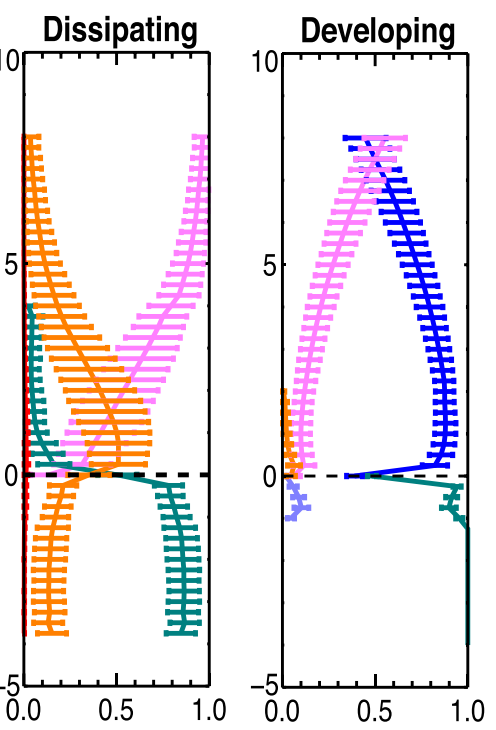

Stratiform
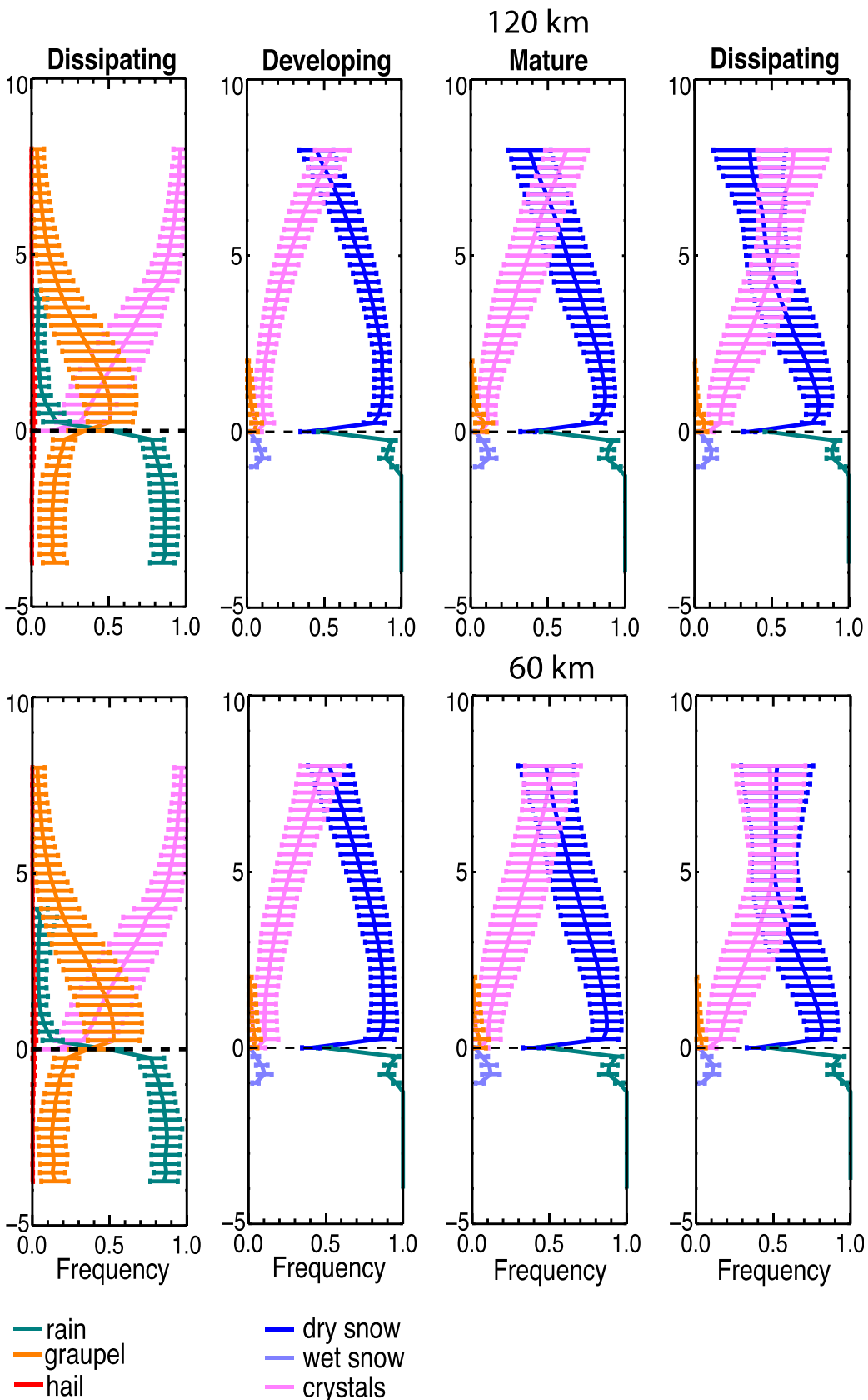

FIG. 6. As in Fig. 5, but for single-radar observations within a range of (top) 120 and (bottom) $60 \mathrm{~km}$ from the radar location. The altitude bin resolution is $0.25 \mathrm{~km}$.

a transition from an environment characterized by $1500 \mathrm{~J} \mathrm{~kg}^{-1}$ of MUCAPE to one of over $2500 \mathrm{~J} \mathrm{~kg}^{-1}$ of MUCAPE yields an increase of graupel frequencies of greater than $50 \%$. More-unstable environments also feature greater frequencies of liquid water above the $0^{\circ} \mathrm{C}$ level than do weaker MUCAPE environments. However, there is an unexpected sensitivity found between hail and MUCAPE. In particular, Fig. 7 shows that the highest averaged frequencies of hail below the $0^{\circ} \mathrm{C}$ level are found in relatively lower MUCAPE environments.

To develop a deeper understanding of the source of the apparent relationship between the hail classification frequency and MUCAPE, similar profiles, color filled by 

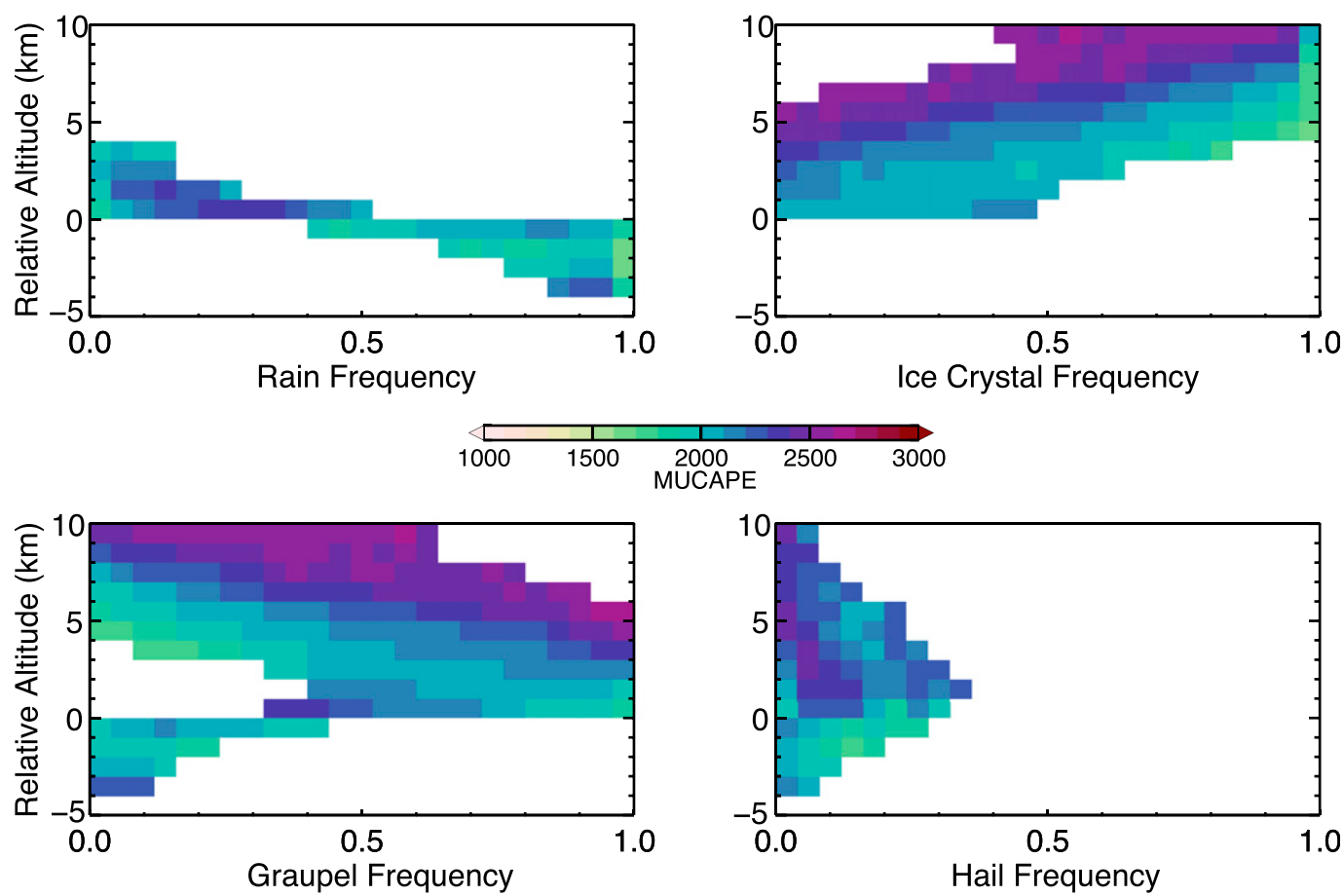

FIG. 7. MUCAPE fill plots for individual storms within the convective region of mature LLTS systems. Each of the four boxes represents a hydrometeor class profile (rain, ice crystals, graupel, and hail), with the MUCAPE values corresponding to observed hydrometeor fractions within individual storms color filled at each altitude (relative to the environmental $0^{\circ} \mathrm{C}$-level altitude). The altitude bin resolution is $1 \mathrm{~km}$ and the frequency bin resolution is 0.05 . A frequency of 1 is equal to $100 \%$.

the four polarimetric radar variables, are shown in Fig. 8. This analysis demonstrates that, regardless of hail frequencies above/below the $0^{\circ} \mathrm{C}$ level altitude, $Z_{\mathrm{DR}}$ and $K_{\mathrm{DP}}$ increase with decreasing altitude and $\rho_{\mathrm{HV}}$ decreases with decreasing altitude. In addition, $Z_{H}$ ranges from approximately 50 to $55 \mathrm{~dB} Z$ throughout, with the largest values found at higher frequencies of hail. Taken together, we expect these polarimetric signatures to indicate that, rather than moderate-to-large hail, the hail hydrometeors classified within LLTS MCSs in this study are predominantly small and melting, or may have already completely melted and subsequently are seeing a signature of large drops. In particular, the higher values of $K_{\mathrm{DP}}$ as altitude decreases (up to $2^{\circ} \mathrm{km}^{-1}$ or greater) can be indicative of raindrop shedding from melting hail (Rasmussen and Heymsfield 1987; Hubbert et al. 1998) or large liquid drops that were formed from completely melted hailstones (Loney et al. 2002).

To further test this hypothesis, convective cores were classified into "small hail" or "moderate hail" categories. In particular, a convective core containing hail was classified as small hail if HA classifications were not found within the lowest $2 \mathrm{~km}$ of the core and moderate hail otherwise. Figure 9 presents the MUCAPE sensitivity plots for rain, nonrimed ice, graupel, and hail hydrometeor classes for convective cores in each category. For moderate hail-labeled convective cores (which are relatively rare), the sensitivity of the hail classification to MUCAPE now agrees with the expected result (i.e., higher MUCAPE is associated with higher frequencies of hail classification). For small hail-labeled convective cores, the result mimics that in the analysis of all cores (Fig. 7).

Vertical wind shear also plays a role in LLTS system hydrometeor distributions. Environments characterized by strong 0-6-km bulk shear greater than $40 \mathrm{kt}$ $\left(1 \mathrm{kt}=\sim 0.51 \mathrm{~m} \mathrm{~s}^{-1}\right)$ are associated with an increased production of rimed iced hydrometeors above and below the environmental $0^{\circ} \mathrm{C}$ level, as shown in Fig. 10 . This sensitivity is strongest for hail. Figure 11 shows that convective cores labeled as moderate hail show consistent hail sensitivity to $0-6-\mathrm{km}$ shear, with larger magnitudes than that observed both overall (Fig. 10) and in the small-hail cores. Differences in the sensitivity of the remaining hydrometeors to $0-6-\mathrm{km}$ shear in small- and moderate-hail storms are qualitatively 

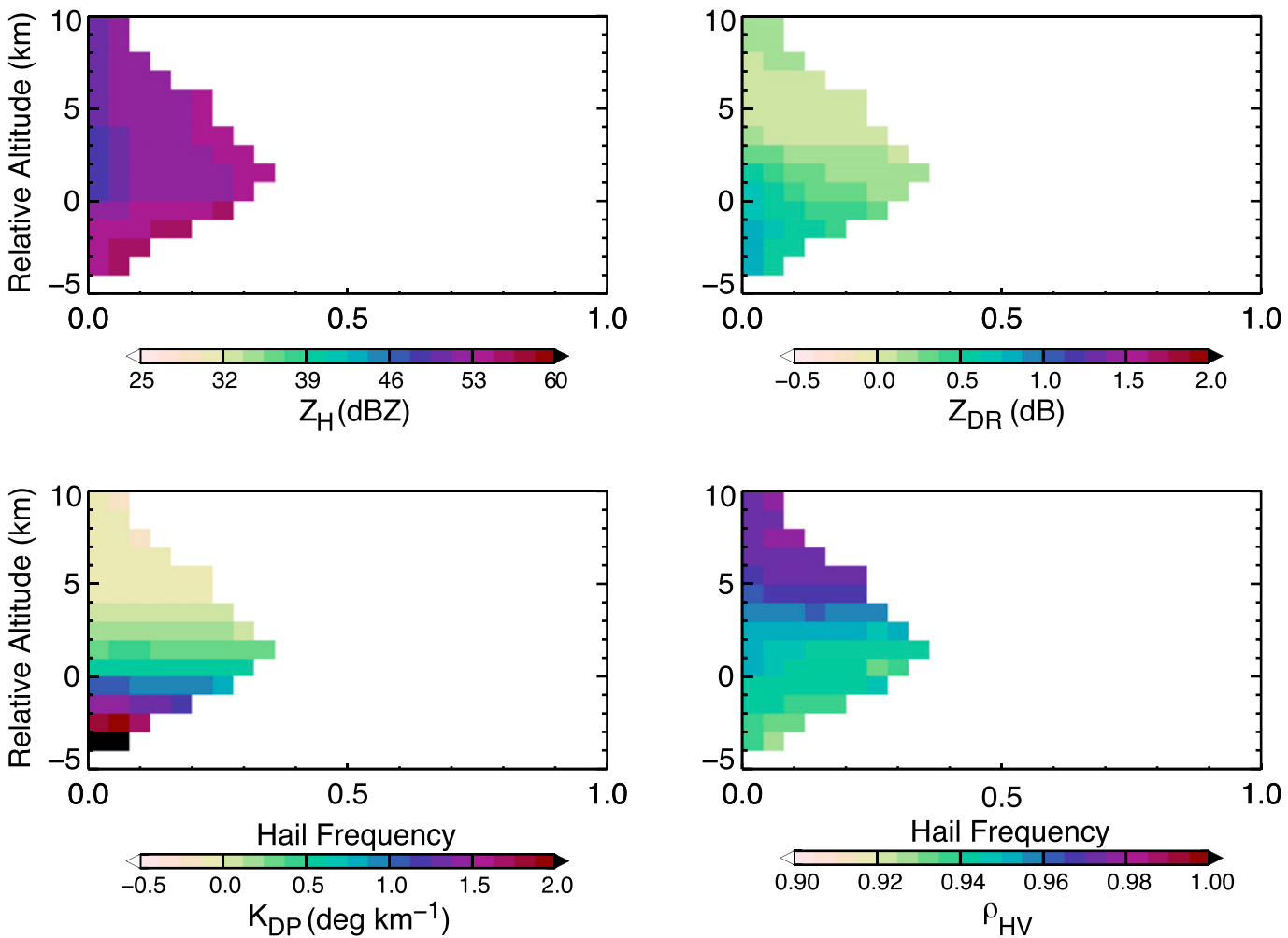

FIG. 8. As in Fig. 7, but for the hail hydrometeor class only and with the color fill corresponding to the mean values of the polarimetric radar variables $Z_{H}, Z_{\mathrm{DR}}, K_{\mathrm{DP}}$, and $\rho_{\mathrm{HV}}$.

similar to those found for MUCAPE. However, it appears from this analysis that vertical wind shear has a minimal impact on the presence of liquid water above the $0^{\circ} \mathrm{C}$ level.

\section{Summary and discussion}

In this study, polarimetric radar observations, a novel radar echo classification algorithm, a hydrometeor classification algorithm, and a reanalysis dataset were leveraged to develop a deeper understanding of the observed bulk microphysics of leading-line trailingstratiform MCSs. These systems were also evaluated in light of their life cycle and the environment in which they form.

First, the polarimetric variables were analyzed. Convective precipitation in LLTS systems is generally characterized by $Z_{H}$ in the range of $30-50 \mathrm{~dB} Z, Z_{\mathrm{DR}}>$ $1 \mathrm{~dB}$ below the $0^{\circ} \mathrm{C}$ level decreasing to near $0 \mathrm{~dB}$ above, $K_{\text {DP }}$ slightly greater than $1^{\circ} \mathrm{km}^{-1}$ below the $0^{\circ} \mathrm{C}$ level, and a broad $\rho_{\mathrm{HV}}$ reduction extending from $3 \mathrm{~km}$ below the $0^{\circ} \mathrm{C}$ level to $6 \mathrm{~km}$ above it. Nonzero values for $Z_{\mathrm{DR}}$ and $K_{\mathrm{DP}}$ reveal more oblate raindrops are present, while aloft near-zero $Z_{\mathrm{DR}}$ indicates more spherical particles. The broad $\rho_{\mathrm{HV}}$ is most likely associated with the coexistence of ice and liquid precipitation. Stratiform precipitation in LLTS systems is characterized by slightly reduced values in $Z_{H}, Z_{\mathrm{DR}}$, and $K_{\mathrm{DP}}$ fields. As is to be expected, the greatest difference is within the $\rho_{\mathrm{HV}}$ field and is attributed to the radar brightband signature. The brightband signature is more pronounced in the single-radar analysis than in the composite analysis, likely as a result of the increased vertical resolution.

Vertical hydrometeor frequency profiles for the convective region revealed a prominent graupel-nose feature extending $\sim 5 \mathrm{~km}$ above the $0^{\circ} \mathrm{C}$ level, high rain frequencies below the $0^{\circ} \mathrm{C}$ level, modest supercooled liquid frequencies of $\sim 5 \%-10 \%$ of the time up to $4 \mathrm{~km}$ above the $0^{\circ} \mathrm{C}$ level, and high frequencies of various ice crystals aloft approaching cloud top. In stratiform regions, dry snow aggregates were most frequently classified in a layer $0-5 \mathrm{~km}$ above the $0^{\circ} \mathrm{C}$ level, while pristine ice crystals become the more frequently classified hydrometeor class at higher altitudes. Graupel was classified up to $10 \%$ on average in a shallow layer above and below the $0^{\circ} \mathrm{C}$ level, while the rain class was the most frequently classified hydrometeor class below the $0^{\circ} \mathrm{C}$ level. While there has been documentation of graupel above the $0^{\circ} \mathrm{C}$ level within stratiform regions 


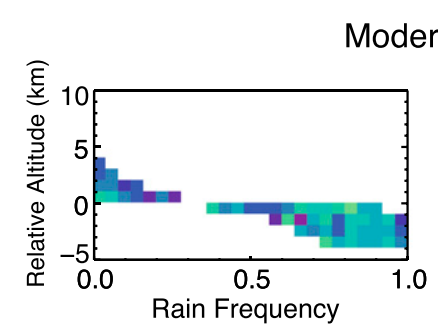

Moderate hail

Small hail
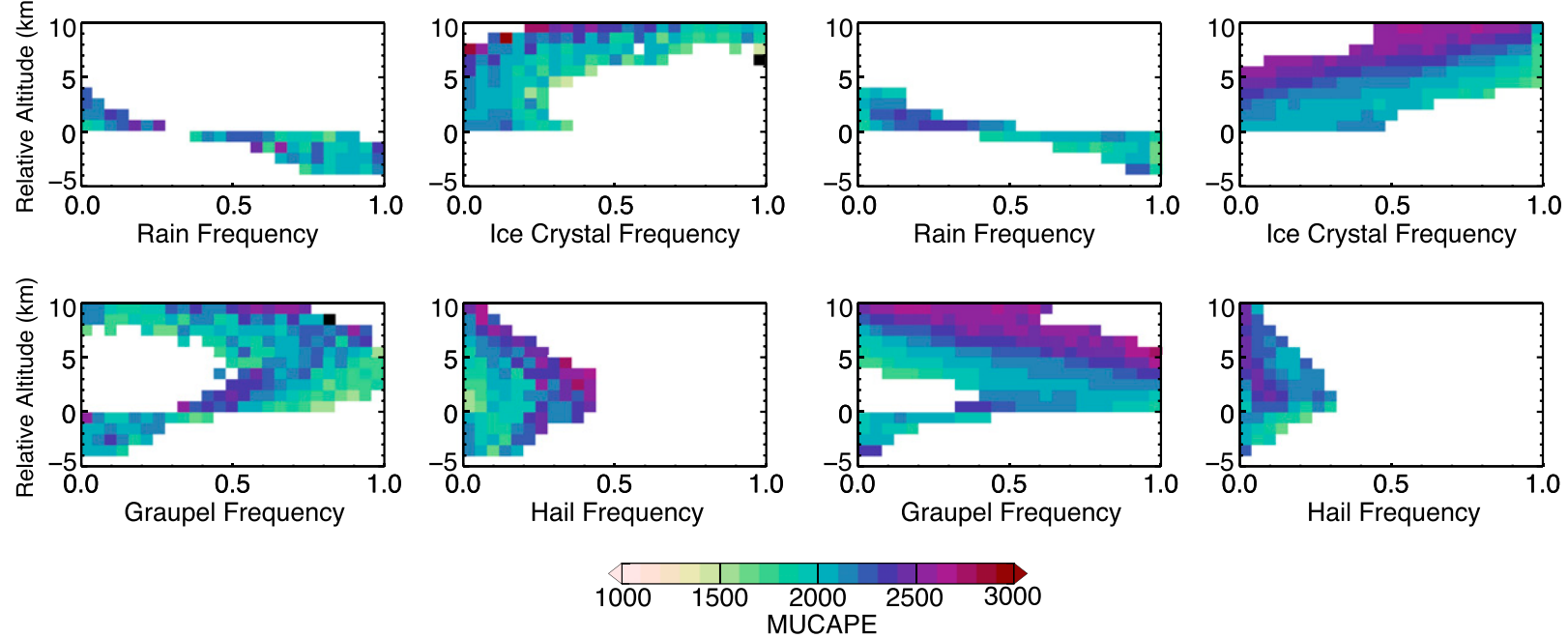

FIG. 9. As in Fig. 7, but for individual convective cores categorized as (left) moderate and (right) small hail.

in previous studies, the percentages here may be slightly overestimated given the nearly identical membership functions for dry snow and graupel. In situ aircraft observations are likely needed to address this issue.

The observations were also used to show that the environment in which an LLTS MCS forms and traverses has a significant impact on rimed ice production within convection. In general, in more-unstable environments along with moderately strong $0-6-\mathrm{km}$ vertical wind shear, increased graupel classification frequencies are seen at and above the environmental $0^{\circ} \mathrm{C}$ level, whereas the opposite is true for less-unstable or lowershear environments. Hailstones are more frequently classified in higher-MUCAPE environments (as expected), but hail is rarely classified near the surface
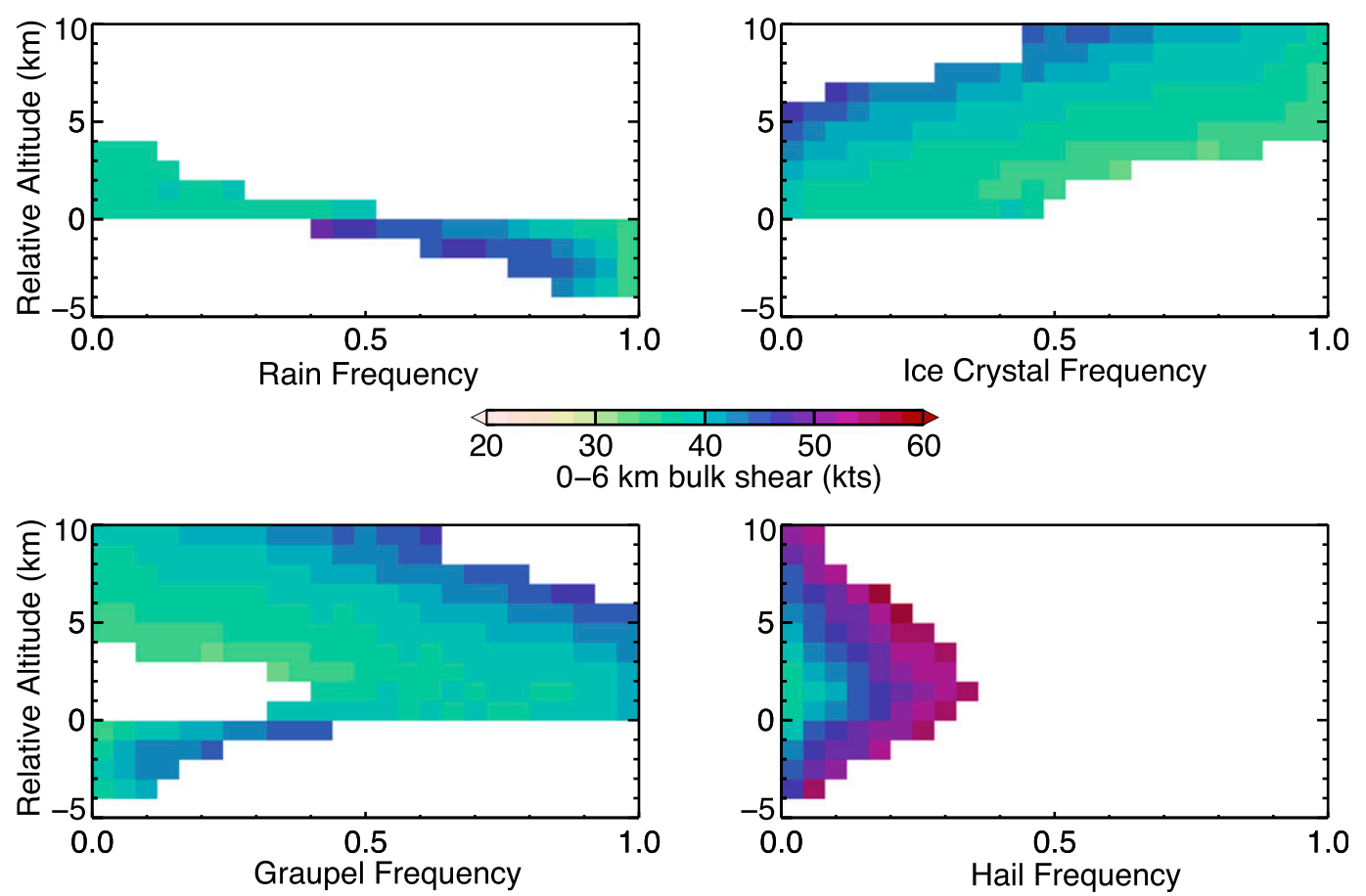

FIG. 10. Similar to Fig. 7, except 0-6-km bulk shear is the color-filled variable. 

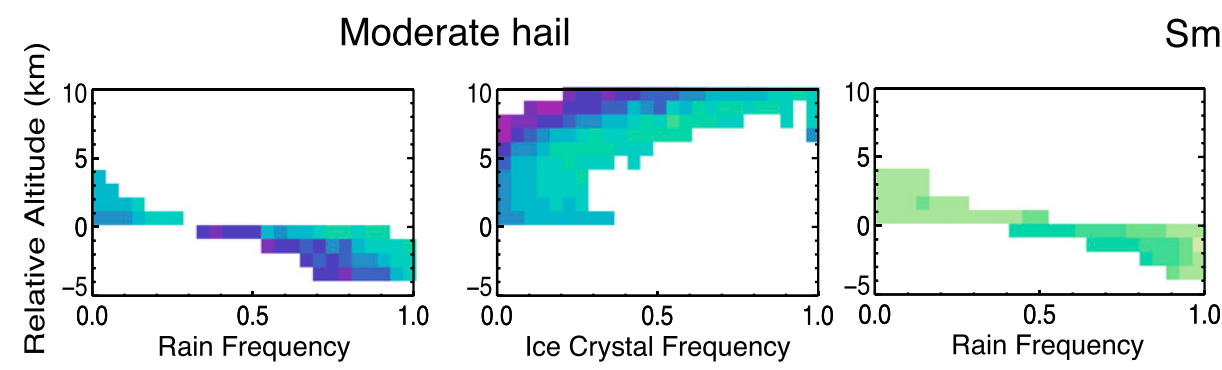

Small hail
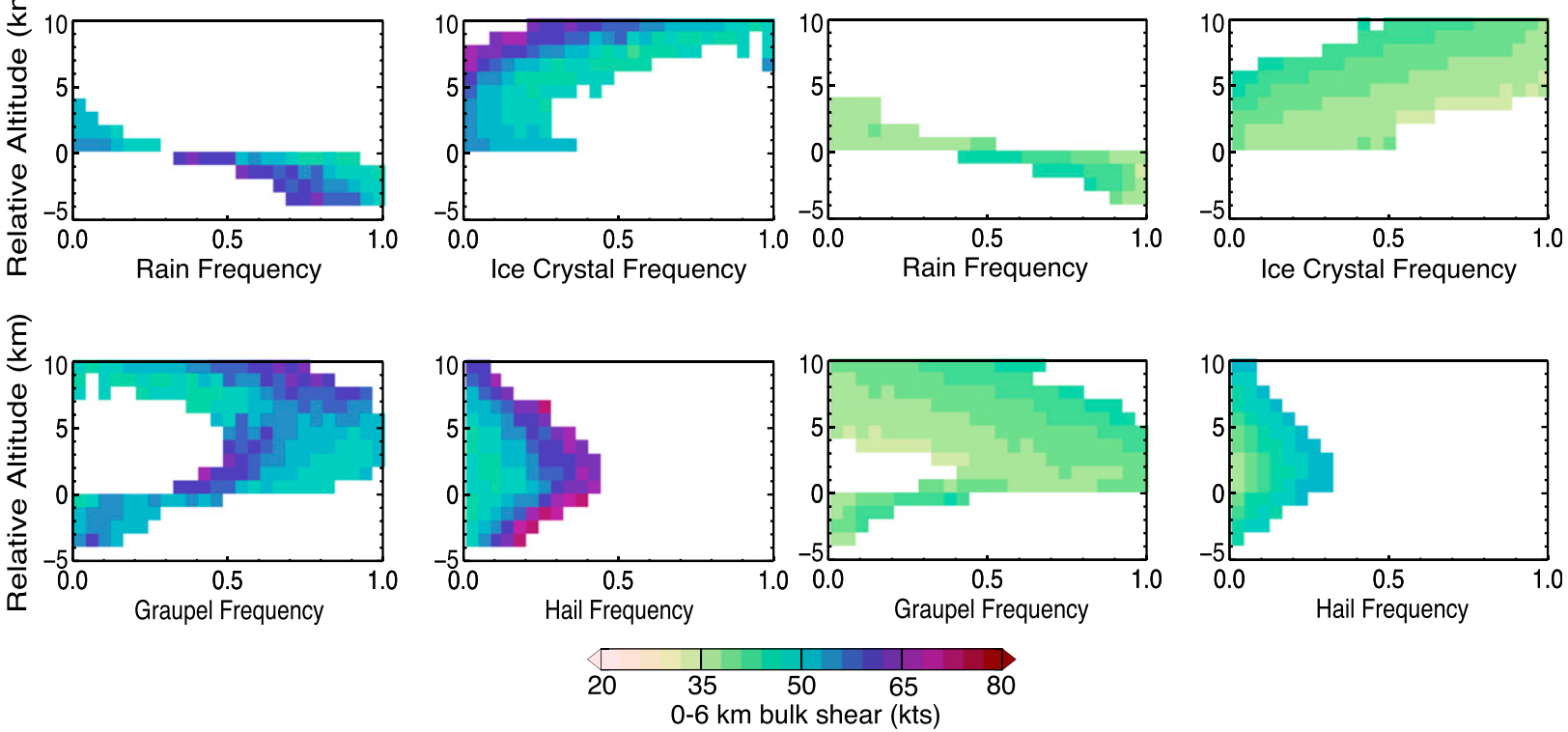

FIG. 11. Similar to Fig. 9, except 0-6-km bulk shear is the color-filled variable.

within the analyzed MCSs. Most hailstones in these LLTS systems melt before reaching the surface, which is why the analysis of all convective cores mimics the small-hail core analysis in this study. The extent to which liquid hydrometeors are lofted is also greater for moreunstable environments, but little sensitivity of rain above the $0^{\circ} \mathrm{C}$ level was found to the bulk shear. More liquid water above the $0^{\circ} \mathrm{C}$ level would subsequently lead to more frequent riming, which is consistent with the observed increase in graupel for higher MUCAPE environments.

Our results show differences between continental LLTS MCSs and those in the literature (Rowe and Houze 2014; Barnes and Houze 2014). Continental LLTS MCSs tend to have higher fractions of graupel and hail within the convective region compared to the oceanic MCSs associated with the MJO. The reasoning for this may be due to differences in the typical thermodynamic profile and convective intensity for each region. Stratiform regions were more similar between oceanic and continental MCSs in comparison with the convective region. Dry snow aggregates tend to dominate close to the $0^{\circ} \mathrm{C}$ level, with more various ice crystals aloft. Graupel was found to be near the $0^{\circ} \mathrm{C}$ level, although we are unable to comment on the spatial pattern of graupel as per Barnes and Houze (2014).

It is important to note that the conclusions drawn from this study may be sensitive to the HCA employed. For example, this study could have been conducted using the NCAR particle identification (PID) algorithm
(Vivekanandan et al. 1999), which may have led to quantitative differences in the results. Thus, it is emphasized here that the understanding of the vertical hydrometeor frequency distributions developed using the NEXRAD observations should be primarily viewed in a qualitative sense. Future work is needed to evaluate the sensitivities of these results to the use of alternative HCAs and novel in situ observations.

The single-radar-based analyses should also be taken in more of a qualitative sense because of the assumption of $\mathbf{Q}$ being set equal to 1 . While we would expect quantitatively different results with the full and newly updated HCA that is operationally implemented for NEXRAD instruments, we believe the qualitative results would be similar to those found here.

The use of a large number of polarimetric radar observations in this study has enabled an increased understanding of the bulk hydrometeor distributions within continental midlatitude LLTS MCSs. Such an increased understanding may lead to future improvements in the representation of microphysical processes within numerical models, along with tools used for model evaluation such as forward operators. The authors recommend that more studies of this kind be conducted, with potential foci of alternative modes of convection, tropical cyclones, and winter storms.

Acknowledgments. We thank NCEI for providing access to the NEXRAD WSR-88D observations and 
NCAR for providing access to NARR output on the NCAR Research Data Archive. We also thank David Parsons and Guifu Zhang at the University of Oklahoma for their insightful comments. This work was supported (in part) by the National Science Foundation (NSF) under Grant AGS-1522910.

\section{REFERENCES}

Andric, J., M. R. Kumjian, D. S. Zrnić, J. M. Straka, and V. M. Melnikov, 2013: Polarimetric signatures above the melting layer in winter storms: An observational and modeling study. J. Appl. Meteor. Climatol., 52, 682-700, https:// doi.org/10.1175/JAMC-D-12-028.1.

Austin, P. M., and A. C. Bemis, 1950: A quantitative study of the bright band in radar precipitation echoes. J. Meteor., 7, 145-151, https://doi.org/10.1175/1520-0469(1950)007<0145: $\mathrm{AQSOTB}>2.0 . \mathrm{CO} ; 2$.

Bader, M., S. Clough, and G. Cox, 1987: Aircraft and dual polarization radar observations of hydrometeors in light stratiform precipitation. Quart. J. Roy. Meteor. Soc., 113, 491-515, https://doi.org/10.1002/qj.49711347605.

Barnes, H., and R. Houze Jr., 2014: Precipitation hydrometeor type relative to the mesoscale airflow in mature oceanic deep convection of the Madden-Julian oscillation. J. Geophys. Res. Atmos., 119, 13 990-14 014, https://doi.org/10.1002/ 2014JD022241.

Biggerstaff, M., and R. Houze Jr., 1991: Kinematic and precipitation structure of the 10-11 June 1985 squall line. Mon. Wea. Rev., 119, 3034-3065, https://doi.org/10.1175/1520-0493(1991) $119<3034:$ KAPSOT>2.0.CO;2.

Bouniol, D., J. Delanoë, C. Duroure, A. Protat, V. Giraud, and G. Penide, 2010: Microphysical characterisation of West African MCS anvils. Quart. J. Roy. Meteor. Soc., 136 (S1), 323344, https://doi.org/10.1002/qj.557.

Brandes, E., J. Vivekanandan, J. Tuttle, and C. Kessinger, 1995: A study of thunderstorm microphysics with multiparameter radar and aircraft observations. Mon. Wea. Rev., 123, 3129-3143, https://doi.org/10.1175/1520-0493(1995) $123<3129$ :ASOTMW $>2.0 . \mathrm{CO} ; 2$.

Bringi, V. N., and V. Chandrasekar, 2001: Polarimetric Doppler Weather Radar. Cambridge University Press, $636 \mathrm{pp}$.

Bryan, G. H., and H. Morrison, 2012: Sensitivity of a simulated squall line to horizontal resolution and parameterization of microphysics. Mon. Wea. Rev., 140, 202-225, https://doi.org/ 10.1175/MWR-D-11-00046.1.

Caylor, I., and A. Illingworth, 1987: Radar observations and modelling of warm rain initiation. Quart. J. Roy. Meteor. Soc., 113, 1171-1191, https://doi.org/10.1002/qj.49711347806.

Cunning, J. B., 1986: The Oklahoma-Kansas Preliminary Regional Experiment for STORM-Central. Bull. Amer. Meteor. Soc., 67, 1478-1486, https://doi.org/10.1175/1520-0477(1986) 067<1478:TOKPRE $>2.0 . \mathrm{CO} ; 2$.

Davis, C., and Coauthors, 2004: The Bow Echo and MCV Experiment: Observations and opportunities. Bull. Amer. Meteor. Soc., 85, 1075-1093, https://doi.org/10.1175/BAMS-85-8-1075.

Doviak, R. J., and D. S. Zrnić, 1993: Doppler Radar and Weather Observations. 2nd ed. Dover Publications, 562 pp.

Evaristo, R., G. Scialom, N. Viltard, and Y. Lemaître, 2010: Polarimetric signatures and hydrometeor classification of West African squall lines. Quart. J. Roy. Meteor. Soc., 136 (S1), 272288, https://doi.org/10.1002/qj.561.
Fabry, F., and I. Zawadzki, 1995: Long-term radar observations of the melting layer of precipitation and their interpretation. J. Atmos. Sci., 52, 838-851, https://doi.org/10.1175/ 1520-0469(1995)052<0838:LTROOT >2.0.CO;2.

Fovell, R. G., 2002: Upstream influence of numerically simulated squall-line storms. Quart. J. Roy. Meteor. Soc., 128, 893-912, https://doi.org/10.1256/0035900021643737.

Hall, M. P., J. W. Goddard, and S. M. Cherry, 1984: Identification of hydrometeors and other targets by dual-polarization radar. Radio Sci., 19, 132-140, https://doi.org/10.1029/ RS019i001p00132.

Homeyer, C., 2014: Formation of the enhanced-V infrared cloudtop feature from high-resolution three-dimensional radar observations. J. Atmos. Sci., 71, 332-348, https://doi.org/10.1175/ JAS-D-13-079.1.

— , and M. Kumjian, 2015: Microphysical characteristics of overshooting convection from polarimetric radar observations. J. Atmos. Sci., 72, 870-891, https://doi.org/10.1175/ JAS-D-13-0388.1.

Houze, R. A., Jr., 1989: Observed structure of mesoscale convective systems and implications for large-scale heating. Quart. J. Roy. Meteor. Soc., 115, 425-461, https://doi.org/10.1002/ qj.49711548702.

_ 2004: Mesoscale convective systems. Rev. Geophys., 42, RG4003, https://doi.org/10.1029/2004RG000150.

—, M. Rutledge, M. Biggerstaff, and B. Smull, 1989: Interpretation of Doppler weather radar displays of midlatitude mesoscale convective systems. Bull. Amer. Meteor. Soc., 70, 608-619, https://doi.org/10.1175/1520-0477(1989)070<0608: IODWRD $>2.0 . \mathrm{CO} ; 2$.

— B. Smull, and P. Dodge, 1990: Mesoscale organization of springtime rainstorms in Oklahoma. Mon. Wea. Rev., 118, 613-654, https://doi.org/10.1175/1520-0493(1990)118<0613: MOOSRI $>2.0 . \mathrm{CO} ; 2$.

Hubbert, J., V. Bringi, L. Carey, and S. Bolen, 1998: CSU-CHILL polarimetric radar measurements from a severe hail storm in eastern Colorado. J. Appl. Meteor., 37, 749-775, https:// doi.org/10.1175/1520-0450(1998)037<0749:CCPRMF $>2.0$. $\mathrm{CO} ; 2$.

Jensen, M., and Coauthors, 2016: The Midlatitude Continental Convective Clouds Experiment (MC3E). Bull. Amer. Meteor. Soc., 97, 1667-1686, https://doi.org/10.1175/BAMS-D-14-00228.1.

Keenan, T., and R. Carbone, 1992: A preliminary morphology of precipitation systems in tropical northern Australia. Quart. J. Roy. Meteor. Soc., 118, 283-326, https://doi.org/10.1002/ qj. 49711850406.

Kumjian, M. R., 2013a: Principles and applications of dualpolarization weather radar. Part I: Description of the polarimetric radar variables. J. Oper. Meteor., 1, 226-242, https:// doi.org/10.15191/nwajom.2013.0119.

__ 2013b: Principles and applications of dual-polarization weather radar. Part II: Warm- and cold-season applications. J. Oper. Meteor., 1, 243-264, https://doi.org/10.15191/ nwajom.2013.0120.

- 2013c: Principles and applications of dual-polarization weather radar. Part III: Artifacts. J. Oper. Meteor., 1, 265274, https://doi.org/10.15191/nwajom.2013.0121.

— , and A. V. Ryzhkov, 2008: Polarimetric signatures in supercell thunderstorms. J. Appl. Meteor. Climatol., 47, 1940-1961, https://doi.org/10.1175/2007JAMC1874.1.

$\longrightarrow$, and - 2009: Storm-relative helicity revealed from polarimetric radar measurements. J. Atmos. Sci., 66, 667-685, https://doi.org/10.1175/2008JAS2815.1. 
— , and - 2012: The impact of size sorting on the polarimetric radar variables. J. Atmos. Sci., 69, 2042-2060, https://doi.org/ 10.1175/JAS-D-11-0125.1.

— S. M. Ganson, and A. V. Ryzhkov, 2012: Raindrop freezing in deep convective updrafts: A microphysical and polarimetric model. J. Atmos. Sci., 69, 3471-3490, https://doi.org/10.1175/ JAS-D-12-067.1.

LeMone, M. A., and E. J. Zipser, 1980: Cumulonimbus vertical velocity events in GATE. Part I: Diameter, intensity and mass flux. J. Atmos. Sci., 37, 2444-2457, https://doi.org/10.1175/ 1520-0469(1980)037<2444:CVVEIG > 2.0.CO;2.

$\_, \ldots$, and S. Trier, 1998: The role of environmental shear and thermodynamic conditions in determining the structure and evolution of mesoscale convective systems during TOGA COARE. J. Atmos. Sci., 55, 3493-3518, https://doi.org/ 10.1175/1520-0469(1998)055<3493:TROESA>2.0.CO;2.

Loney, M. L., D. S. Zrnić, J. M. Straka, and A. V. Ryzhkov, 2002: Enhanced polarimetric radar signatures above the melting level in a supercell storm. J. Appl. Meteor., 41, 1179-1194, https://doi.org/10.1175/1520-0450(2002)041<1179:EPRSAT>2.0. $\mathrm{CO} ; 2$.

Mesinger, F., and Coauthors, 2006: North American Regional Reanalysis. Bull. Amer. Meteor. Soc., 87, 343-360, https:// doi.org/10.1175/BAMS-87-3-343.

NCEP, 2005: NCEP North American Regional Reanalysis (NARR). Research Data Archive, Computational and Information Systems Laboratory, National Center for Atmospheric Research, accessed March-August 2016, http:// rda.ucar.edu/datasets/ds608.0/.

NOAA/NWS/ROC, 1991: NOAA Next Generation Radar (NEXRAD) level II base data. NOAA/National Centers for Environmental Information, accessed August-November 2015, https://doi.org/10.7289/V5W9574V.

Ortega, K. L., J. M. Krause, and A. V. Ryzhkov, 2016: Polarimetric radar characteristics of melting hail. Part III: Validation of the algorithm for hail size discrimination. J. Appl. Meteor. Climatol., 55, 829-848, https://doi.org/10.1175/JAMC-D-150203.1.

Pandya, R. E., and D. R. Durran, 1996: The influence of convectively generated thermal forcing on the mesoscale circulation around squall lines. J. Atmos. Sci., 53, 2924-2951, https:// doi.org/10.1175/1520-0469(1996)053<2924:TIOCGT>2.0.CO;2.

Park, H., A. Ryzhkov, D. Zrnić, and K. Kim, 2009: The hydrometeor classification algorithm for the polarimetric WSR-88D: Description and application to an MCS. Wea. Forecasting, 24, 730-748, https://doi.org/10.1175/2008WAF2222205.1.

Parker, M., and R. Johnson, 2000: Organizational modes of midlatitude mesoscale convective systems. Mon. Wea. Rev., 128, 3413-3436, https://doi.org/10.1175/1520-0493(2001)129<3413: $\mathrm{OMOMMC}>2.0 . \mathrm{CO} ; 2$.

Rasmussen, R. M., and A. J. Heymsfield, 1987: Melting and shedding of graupel and hail. Part III: Investigation of the role of shed drops as hail embryos in the 1 August CCOPE severe storm. J. Atmos. Sci., 44, 2783-2803, https://doi.org/10.1175/ 1520-0469(1987)044<2783:MASOGA > 2.0.CO;2.

Rotunno, R., J. B. Klemp, and M. L. Weisman, 1988: A theory for strong, long-lived squall lines. J. Atmos. Sci., 45, 463-485, https://doi.org/10.1175/1520-0469(1988)045<0463:ATFSLL > 2.0. $\mathrm{CO} ; 2$.

Rowe, A., and R. Houze Jr., 2014: Microphysical characteristics of MJO convection over the Indian Ocean during DYNAMO. J. Geophys. Res. Atmos., 119, 2543-2554, https://doi.org/ 10.1002/2013JD020799.
Ryzhkov, A. V., 2007: The impact of beam broadening on the quality of radar polarimetric data. J. Atmos. Oceanic Technol., 24, 729-744, https://doi.org/10.1175/JTECH2003.1.

- M. R. Kumjian, S. M. Ganson, and P. Zhang, 2013: Polarimetric radar characteristics of melting hail. Part II: Practical implications. J. Appl. Meteor. Climatol., 52, 2871-2886, https:// doi.org/10.1175/JAMC-D-13-074.1.

Schmidt, J. M., and W. R. Cotton, 1990: Interactions between upper and lower tropospheric gravity waves on squall line structure and maintenance. J. Atmos. Sci., 47, 1205-1222, https://doi.org/10.1175/1520-0469(1990)047<1205:IBUALT>2.0. $\mathrm{CO} ; 2$.

Seliga, T., and V. Bringi, 1976: Potential use of radar differential reflectivity measurements at orthogonal polarizations for measuring precipitation. J. Appl. Meteor., 15, 69-76, https:// doi.org/10.1175/1520-0450(1976)015<0069:PUORDR>2.0. $\mathrm{CO} ; 2$.

, and - 1978: Differential reflectivity and differential phase shift: Applications in radar meteorology. Radio Sci., 13, 271275, https://doi.org/10.1029/RS013i002p00271.

Smith, P., D. Musil, A. Detwiler, and R. Ramachandran, 1999: Observations of mixed-phase precipitation within a CaPE thunderstorm. J. Appl. Meteor., 38, 145-155, https://doi.org/ 10.1175/1520-0450(1999)038<0145:OOMPPW >2.0.CO;2.

Smull, B. F., and R. A. Houze Jr., 1985: A midlatitude squall line with a trailing region of stratiform rain: Radar and satellite observations. Mon. Wea. Rev., 113, 117-133, https://doi.org/ 10.1175/1520-0493(1985)113<0117:AMSLWA > 2.0.CO;2.

— and — 1987: Rear inflow in squall lines with trailing stratiform precipitation. Mon. Wea. Rev., 115, 2869-2889, https://doi.org/ 10.1175/1520-0493(1987)115<2869:RIISLW > 2.0.CO;2

Starzec, M., C. R. Homeyer, and G. L. Mullendore, 2017: Storm labeling in 3 dimensions (SL3D): A volumetric radar echo and dual-polarization updraft classification algorithm. Mon. Wea. Rev., 145, 1127-1145, https://doi.org/10.1175/ MWR-D-16-0089.1.

Straka, J., D. Zrnić, and A. Ryzhkov, 2000: Bulk hydrometeor classification and quantification using polarimetric radar data: Synthesis of relations. J. Appl. Meteor., 39, 1341-1372, https:// doi.org/10.1175/1520-0450(2000)039<1341:BHCAQU>2.0.CO;2.

Trömel, S., M. R. Kumjian, A. V. Ryzhkov, C. Simmer, and M. Diederich, 2013: Backscatter differential phase-Estimation and variability. J. Appl. Meteor. Climatol., 52, 2529-2548, https://doi.org/10.1175/JAMC-D-13-0124.1.

_ A. V. Ryzhkov, P. Zhang, and C. Simmer, 2014: Investigations of backscatter differential phase in the melting layer. J. Appl. Meteor. Climatol., 53, 2344-2359, https://doi.org/ 10.1175/JAMC-D-14-0050.1.

Vivekanandan, J., S. Ellis, R. Oye, D. Zrnić, A. Ryzhkov, and J. Straka, 1999: Cloud microphysics retrieval using S-band dual-polarization radar measurements. Bull. Amer. Meteor. Soc., 80, 381-388, https://doi.org/10.1175/1520-0477(1999) $080<0381$ :CMRUSB $>2.0$. CO 2 .

Weisman, M. L., and J. B. Klemp, 1982: The dependence of numerically simulated convective storms on vertical wind shear and buoyancy. Mon. Wea. Rev., 110, 504-520, https://doi.org/ 10.1175/1520-0493(1982)110<0504:TDONSC $>2.0 . C O ; 2$.

_, _ _ , and R. Rotunno, 1988: Structure and evolution of numerically simulated squall lines. J. Atmos. Sci., 45, 1990-2013, https://doi.org/10.1175/1520-0469(1988)045<1990: SAEONS $>2.0 . \mathrm{CO} ; 2$

Yuter, S. E., and R. A. Houze, 1995: Three-dimensional kinematic and microphysical evolution of Florida cumulonimbus. 
Part II: Frequency distributions of vertical velocity, reflectivity, and differential reflectivity. Mon. Wea. Rev., 123, 1941-1963, https://doi.org/10.1175/1520-0493(1995)123<1941: TDKAME $>2.0 . \mathrm{CO} ; 2$.

Zhang, J., C. Langston, and K. Howard, 2008: Brightband identification based on vertical profiles of reflectivity from the WSR-88D. J. Atmos. Oceanic Technol., 25, 1859-1872, https://doi.org/10.1175/2008JTECHA1039.1.

Zipser, E. J., 1969: The role of organized unsaturated convective downdrafts in the structure and rapid decay of an equatorial disturbance. J. Appl. Meteor., 8, 799-814, https:// doi.org/10.1175/1520-0450(1969)008<0799:TROOUC $>2.0$. $\mathrm{CO} ; 2$.
__ 1977: Mesoscale and convective scale downdrafts as distinct components of squall-line structure. Mon. Wea. Rev., 105, 1568-1589, https://doi.org/10.1175/1520-0493(1977)105<1568: MACDAD $>2.0 . \mathrm{CO} ; 2$.

— events in GATE. Part II: Synthesis and model core structure. J. Atmos. Sci., 37, 2458-2469, https://doi.org/10.1175/ 1520-0469(1980)037<2458:CVVEIG>2.0.CO;2.

Zrnić, D., N. Balakrishnan, C. Ziegler, V. Bringi, K. Aydin, and T. Matejka, 1993: Polarimetric signatures in the stratiform region of a mesoscale convective system. J. Appl. Meteor. 32, 678-693, https://doi.org/10.1175/1520-0450(1993)032<0678: PSITSR $>2.0 . \mathrm{CO} ; 2$. 